\title{
Temperature-dependent bursting pattern analysis by modified Plant model
}

\author{
Nam Gyu Hyun ${ }^{1}$, Kwang-Ho Hyun², Kwang-Beom Hyun ${ }^{3}$ and Kyungmin Lee ${ }^{4^{*}}$
}

\begin{abstract}
Many electrophysiological properties of neuron including firing rates and rhythmical oscillation change in response to a temperature variation, but the mechanism underlying these correlations remains unverified. In this study, we analyzed various action potential (AP) parameters of bursting pacemaker neurons in the abdominal ganglion of Aplysia juliana to examine whether or not bursting patterns are altered in response to temperature change. Here we found that the inter-burst interval, burst duration, and number of spike during burst decreased as temperature increased. On the other hand, the numbers of bursts per minute and numbers of spikes per minute increased and then decreased, but interspike interval during burst firstly decreased and then increased. We also tested the reproducibility of temperature-dependent changes in bursting patterns and AP parameters. Finally we performed computational simulations of these phenomena by using a modified Plant model composed of equations with temperature-dependent scaling factors to mathematically clarify the temperature-dependent changes of bursting patterns in burst-firing neurons. Taken together, we found that the modified Plant model could trace the ionic mechanism underlying the temperature-dependent change in bursting pattern from experiments with bursting pacemaker neurons in the abdominal ganglia of Aplysia juliana.
\end{abstract}

Keywords: Temperature dependence, Bursting patterns, Modified Plant model, R15 pacemaker neuron, Aplysia juliana

\section{Introduction}

To date, researchers have investigated the effect of temperature on the electrical activity and firing patterns in neurons from many animals, including Aplysia juliana, crabs, crayfish, frogs, lobsters, locusts, snails, and squids [1-9]. Especially the functions and properties of bursting pacemaker neuron R15 in the abdominal ganglion of Aplysia have been extensively studied [10-12] and mathematical simulation of bursting activity has been successfully performed [13-19]. However, few studies on the temperature dependence of action potential (AP) parameters in the R15 bursting pacemaker neuron have been reported [20,21]. They analyzed typical changes of AP parameters in burst-firing neurons by investigating the effect of heat on R15 bursting pacemaker neuron activity as the temperature increased and reported temperaturedependent changes in inter-burst interval, burst duration,

\footnotetext{
* Correspondence: irislkm@knu.ac.kr

${ }^{4}$ Department of Anatomy, Brain Science \& Engineering Institute, Kyungpook National University Graduate School of Medicine, 2-101, Dongin-dong, Jung-gu, Daegu 700-842, South Korea

Full list of author information is available at the end of the article
}

number of spike per burst, intra-burst spike broadening and spike height [21]. However, the reproducible properties and mechanism of temperature-dependent changes of AP parameters remain unknown yet.

Changes in temperature can produce numerous effects on the neural tissue of most organisms. Indeed it has been reported that hyperthermic temperature may induce depolarization and spontaneous firing of pyramidal neurons leading to enhanced excitability of hippocampus $[22,23]$. On the other hand, a body of evidence indicating a therapeutic effect of hypothermia has accumulated in several conditions. Orlowski and colleagues published that in refractory status epilepticus unresponsive to conventional treatment, systemic hypothermia $\left(30-31^{\circ} \mathrm{C}\right)$ was an effective therapeutic method leading to burst suppression on electroencephalography (EEG) [24]. Despite a lot of works aiming at demonstrating the neural effect of temperature, the mechanism of temperaturedependent electrophysiological change containing alteration of bursting and firing pattern in neuron remains unclear. Here, we examined the effects of temperature 
changes on the neuronal activity and bursting patterns during several consecutive heating-cooling cycles by using bursting pacemaker neurons which are a proper specimen with capability of long-lasting recording for mathematical modeling. Next, we sought to identify the mechanism underlying temperature-dependent bursting patterns of these neurons by analyzing and comparing the experimental data to computational simulation data calculated by modified Plant equations with temperaturedependent scaling factors, $\rho(\mathrm{T})$ and $\phi(\mathrm{T})$.

\section{Materials and methods}

\section{Animals and dissection}

Animals (A. juliana) were collected locally in Seogwipo, South Korea and all experimental procedures were approved by the Jeju National University Animal Care and Use Committee. These animals were dissected to observe the temperature-dependency of bursting patterns generated by pacemaker neurons R15 in the abdominal ganglia of A. juliana as described in previously published paper [1]. Briefly, the animals were anesthetized with an injection of $0.38 \mathrm{M} \mathrm{MgCl}_{2}$ amounting to half of each specimen's weight before the abdominal ganglia were removed. Each abdominal ganglion was incubated at $34^{\circ} \mathrm{C}$ for 40 minute in a solution containing equal volumes of artificial sea water (ASW; in mM: $460 \mathrm{NaCl}, 10 \mathrm{KCl}, 11$ $\mathrm{CaCl}_{2}, 55 \mathrm{MgCl}_{2}$, and 10 HEPES; $\mathrm{pH}$ 7.6) and isotonic Leibovitz's L-15 media (Cat. No. L-4386; Sigma) containing $1 \%$ protease (type IX; Sigma) (hereafter, ASW:L-15 $(1: 1))$. They were then washed several times with ASW and were placed in a low-temperature incubator (VS1203PIN; Hanback Co., Daejeon, Korea) at $18^{\circ} \mathrm{C}$. At last they were removed onto Petri dishes $(50 \times 9 \mathrm{~mm})$, pinned down on Sylgard plates (Dow Corning, USA) filled with ASW:L-15(1:1), and desheathed.

\section{Data acquisition and analysis}

A PT100 platinum resistance temperature sensor connected to a digital thermometer (TRM-006, Toho, Japan) was placed near the abdominal ganglia of Aplysia soaked in ASW:L-15 (1:1, v/v) to measure the medium temperature, which could be increased or decreased by activating the temperature controller system (HMN 3940, Acetec Co., Korea). We used a low flow rate peristaltic pump (BJ100-2 J; Baoding Longer Precision Pump Co., China) to maintain a viable solution with ASW:L-15 (1:1) media. The flow rate and the speed were $0.14 \mathrm{~mL} / \mathrm{min}$ and $1.0 \mathrm{rpm}$, respectively. Intracellular recordings of bursting pacemaker neurons were performed to measure the membrane potential. The glass intracellular electrodes were filled with $3 \mathrm{M} \mathrm{KCl}$ and the membrane potentials recorded were simultaneously saved using a DAQ card (NI PCI-6221, National Instruments) and the Labview program (National Instruments). The electrical signals of the APs were identified using a digital oscilloscope (54622A; Agilent, Colorado Springs, Colo., USA). These data were recorded at a rate of $3 \mathrm{kHz}$ to reproduce the APs on the computer because the bursting cells generated APs at a rate of $0-4 \mathrm{~Hz}$; each component of this data is composed of 180,000 pairs of temperature and membrane potential values with unique file names, and the dataset was composed of 1,713 files as shown in Table 1 . With this selected dataset, the average values of each of the AP parameters of the burst-firing neuron could be calculated using Origin 6.0 (Microcal Software, Inc.) and a computer program we designed. For each experiment, the bursting neuron was held at room temperature for one hour as shown in Table 2 and then changed with continuous ramp from about $16^{\circ} \mathrm{C}$ to $30^{\circ} \mathrm{C}$. Then, the data recorded by increments (or decrements) of $2^{\circ} \mathrm{C}$ from about $16^{\circ} \mathrm{C}$ to $30^{\circ} \mathrm{C}$ (16-18-20-22-24-26-

Table 1 Animal weights and electrophysiological properties of signals generated by eight R15 bursting pacemaker neurons in A. juliana specimens

\begin{tabular}{|c|c|c|c|c|c|c|c|}
\hline \multirow[b]{2}{*}{ Exp. } & \multirow[b]{2}{*}{$\begin{array}{l}\text { Animal } \\
\text { weight } \\
\text { (g) }\end{array}$} & \multicolumn{4}{|c|}{ Data selected for analysis } & \multirow[b]{2}{*}{$\begin{array}{l}\text { Total } \\
\text { number } \\
\text { of spikes }\end{array}$} & \multirow[b]{2}{*}{$\begin{array}{l}\text { Total } \\
\text { recording } \\
\text { time (min) }\end{array}$} \\
\hline & & $\begin{array}{l}\text { Range of } \\
\text { temperature } \\
\text { change }\left({ }^{\circ} \mathrm{C}\right)\end{array}$ & $\begin{array}{l}\text { Time interval } \\
\text { for analysis } \\
\text { (min) }\end{array}$ & $\begin{array}{l}\text { Number of } \\
\text { tem. change } \\
\text { cycle }\end{array}$ & $\begin{array}{l}\text { Number } \\
\text { of spikes }\end{array}$ & & \\
\hline$A$ & 150 & $16.5-30.0$ & 231 & $2(8)$ & 7,861 & 31,890 & 980 \\
\hline B & 130 & $16.7-29.8$ & 230 & $2(6)$ & 9,030 & 25,890 & 794 \\
\hline C & 190 & $14.5-30.8$ & 210 & $2(3)$ & 3,640 & 6,230 & 491 \\
\hline $\mathrm{D}$ & 210 & $14.4-29.5$ & 137 & $1(1)$ & 4,776 & 9,121 & 292 \\
\hline$E$ & 290 & $13.5-30.3$ & 225 & $2(4)$ & 6,670 & 18,668 & 623 \\
\hline$F$ & 255 & $17.3-32.5$ & 228 & $2(5)$ & 3,613 & 10,500 & 674 \\
\hline G & 310 & $14.4-30.9$ & 225 & $2(4)$ & 3,884 & 10,168 & 570 \\
\hline $\mathrm{H}$ & 280 & $15.8-30.0$ & 227 & $2(3)$ & 3,994 & 7,848 & 433 \\
\hline Total & - & - & 1,713 & $15(33)$ & 43,468 & 120,315 & 4,857 \\
\hline Average & 226 & $15.3-30.4$ & 214 & $2(4)$ & 5,433 & 15,039 & 607 \\
\hline
\end{tabular}

Exp., Experiments; temp., temperature; ( ), total number of temperature change cycle. 
Table 2 Temperature and selected AP parameters in bursting pacemaker neurons maintained for $\mathbf{3 0}$ min

\begin{tabular}{llllrr}
\hline Experiments & Temperature & $\begin{array}{l}\text { Number of } \\
\text { bursts/min }\end{array}$ & $\begin{array}{l}\text { Number of } \\
\text { spikes/burst }\end{array}$ & $\begin{array}{l}\text { Interbust } \\
\text { interval(s) }\end{array}$ & $\begin{array}{l}\text { Burst } \\
\text { duration(s) }\end{array}$ \\
\hline A & $21.48 \pm 0.03$ & $4.86 \pm 0.31$ & $9.49 \pm 0.80$ & $8.72 \pm 0.88$ & $2.77 \pm 0.20$ \\
B & $22.61 \pm 0.01$ & $6.33 \pm 0.36$ & $8.23 \pm 0.53$ & $5.96 \pm 0.66$ & $3.10 \pm 0.16$ \\
C & $19.45 \pm 0.00$ & $2.33 \pm 0.08$ & $9.10 \pm 0.17$ & $19.46 \pm 0.47$ & $2.01 \pm 0.03$ \\
D & $16.34 \pm 0.03$ & $4.63 \pm 0.19$ & $7.71 \pm 0.31$ & $9.07 \pm 0.33$ & $2.95 \pm 0.08$ \\
E & $19.11 \pm 0.02$ & $4.16 \pm 0.17$ & $20.82 \pm 0.71$ & $8.68 \pm 0.65$ & $5.01 \pm 0.10$ \\
F & $22.20 \pm 0.04$ & $3.13 \pm 0.22$ & $6.02 \pm 0.38$ & $14.47 \pm 0.96$ & $3.56 \pm 0.16$ \\
G & $18.22 \pm 0.03$ & $2.43 \pm 0.13$ & $8.64 \pm 0.19$ & $18.79 \pm 0.63$ & $2.37 \pm 0.05$ \\
H & $18.86 \pm 0.02$ & $5.90 \pm 0.38$ & $5.28 \pm 0.22$ & $8.54 \pm 0.73$ & $1.73 \pm 0.07$ \\
Average & $19.78 \pm 0.76$ & $4.22 \pm 0.53$ & $9.41 \pm 1.70$ & $11.71 \pm 1.82$ & $2.93 \pm 0.36$ \\
\hline
\end{tabular}

$28-30^{\circ} \mathrm{C}$ ) were averaged over. To reduce experimental variability, in each experiment the bursting neuron was incubated at least $5 \mathrm{~min}$ to adapt to a new steady-state temperature before recording rhythmic change.

\section{Results}

Definition of AP parameters in burst-firing neuron

The graph in Figure 1A represents the typical bursting patterns of electrical signals shown in Aplysia bursting pacemaker neuron. The intraburst interspike interval, interburst interval, and burst duration are represented by symbols (1), (2), and (3), respectively. The membrane potentials at the positive peak, $\mathrm{V}_{\mathrm{pp}}(\mathrm{mV})$, and negative peak, $V_{n p}(m V)$, are defined as the values of membrane potentials at points $\mathrm{T}$ and $\mathrm{B}$ shown in Figure $1 \mathrm{~B}$, respectively. The definition of the first half of the rising phase of AP, $\Delta t_{\mathrm{r} 1}(\mathrm{~ms})$, and the following AP parameters are very similar to those defined in our previous study [1].
The last half of the rising phase of AP, $\Delta \mathrm{t}_{\mathrm{r} 2}(\mathrm{~ms})$ and the first half of the falling phase of AP, $\Delta \mathrm{t}_{\mathrm{f} 1}(\mathrm{~ms})$ are time intervals shown in Figure 1B. The last half of the falling phase $\Delta \mathrm{t}_{\mathrm{f} 2}(\mathrm{~ms})$ is defined as the values of the time interval between two points $\mathrm{H} 2$ and $\mathrm{B}$ shown in Figure $1 \mathrm{~B}$. The AP half-width duration, $\Delta \mathrm{t}_{\mathrm{AP}, 1 / 2}(\mathrm{~ms})$, is defined as $\Delta \mathrm{t}_{\mathrm{r} 2}+\Delta \mathrm{t}_{\mathrm{f} 1}$ (ms). The interspike interval, ISI (ms), is defined as $\Delta \mathrm{t}_{\mathrm{r} 1}+\Delta \mathrm{t}_{\mathrm{AP}, 1 / 2}+\Delta \mathrm{t}_{\mathrm{f} 2}$. The spontaneous firing frequency, simply referred to as Frequency $\left(\mathrm{s}^{-1}\right)$, is defined as $\operatorname{ISI}^{-1}\left(\mathrm{~s}^{-1}\right)$. For convenience, the average angles $\theta_{1}$ and $\theta_{2}$ are defined to compare the slope of the second half of the rising phase of the AP with that of the first half of the falling phase. The angle $\theta_{1}$ is defined as the inverse tangent of the ratio of half $\mathrm{A}_{\mathrm{AP}}$ to $\Delta \mathrm{t}_{\mathrm{r} 2}$, and the angle $\theta_{2}$ is also defined as the inverse tangent of the ratio of half $\mathrm{A}_{\mathrm{AP}}$ to $\Delta \mathrm{t}_{\mathrm{f} 1}: \theta_{1} \equiv \operatorname{Arctan}\left[\frac{\mathrm{V}\left(\mathrm{t}_{\mathrm{T}}\right)-\mathrm{V}\left(\mathrm{t}_{\mathrm{H} 1}\right)}{\mathrm{t}_{\mathrm{T}}-\mathrm{t}_{\mathrm{H} 1}}\right]$ and $\theta_{2} \equiv$ $\operatorname{Arctan}\left[\frac{\mathrm{V}\left(\mathrm{t}_{\mathrm{T}}\right)-\mathrm{V}\left(\mathrm{t}_{\mathrm{H} 2}\right)}{\mathrm{t}_{\mathrm{H} 2} \mathrm{t}_{\mathrm{T}}}\right]$. Although angles are usually defined
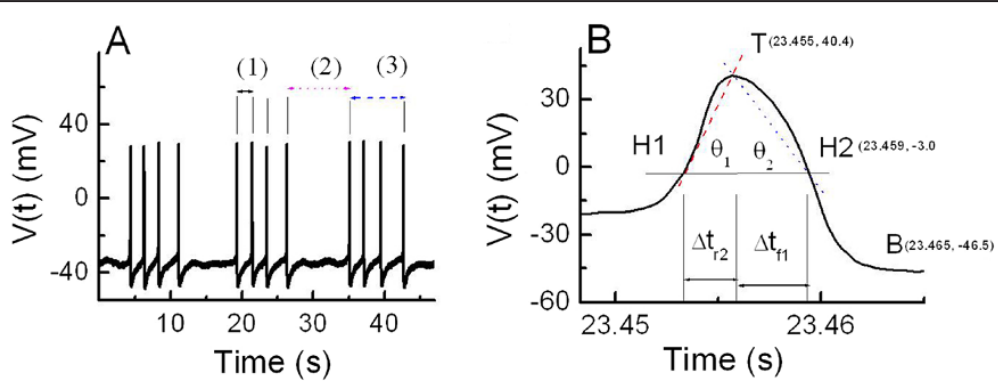

Figure 1 Typical bursting patterns and AP parameters of bursting pacemaker neuron. (A) Bursting patterns of bursting pacemaker neuron; membrane potential vs. time. The electrophysiological parameters related to burst firing contain the intraburst interspike interval, the duration between the two points of sequential $V_{p p}$ within one burst firing event $[\mathbf{A}(1)]$; interburst interval, the duration between the two points of the last $V_{p p}$ of one burst firing event and the first $V_{p p}$ of next burst firing event $[\mathbf{A}(2)]$; and burst duration, the duration between the two points of the first $V_{p p}$ and the last $V_{p p}$ within one burst firing event [A (3)]. (B) Definition of AP parameters. The maximum point $T$ on the upper part of AP means a positive peak membrane potential, $V_{p p}$ and the minimum point $B$ on the lower part of AP means a negative peak membrane potential, $V_{n p} . H 1$ and $\mathrm{H} 2$ means the half point of potential difference during the rising phase and the falling phase of AP, respectively. The last half of the rising phase, $\Delta \mathrm{t}_{\mathrm{r} 2}$ designate the time intervals between the two point $\mathrm{H} 1$ and $\mathrm{T}$. The first half of the falling phase of $\mathrm{AP}, \Delta \mathrm{t}_{\mathrm{f} 1}$ is defined as the time interval between point $\mathrm{T}$ and point $\mathrm{H} 2$. The angle $\theta_{1}$ shows the inverse tangent of the ratio of half $A_{A P}$ to $\Delta t_{r 2}$ and angle $\theta 2$ means the inverse tangent of the ratio of half $\mathrm{A}_{\mathrm{AP}}$ to $\Delta \mathrm{t}_{\mathrm{f}}$. 
as dimensionless quantities, these angles are defined differently for convenience. The AP amplitude, $\mathrm{A}_{\mathrm{AP}}(\mathrm{mV})$, is defined as the absolute value of difference between the two values of membrane potentials at points $\mathrm{T}$ and $\mathrm{B}$, respectively. More detailed analytical techniques regarding the definition and computational analysis of AP parameters and others were described previously $[1,25]$. Data were processed using the scientific data analysis tools, $\mathrm{C}^{++}$, Origin 6.0, and Mathematica 5.1, and the resulting data were presented as mean $\pm \mathrm{SE}$ (standard error).

\section{Structure of the selected dataset for AP parameter analysis}

Eight experiments $(\mathrm{A}-\mathrm{H})$ were conducted using A. juliana specimens, and Table 1 shows the animal weights, selected data for analysis, total number of spike, and total recording time.

Animal weights were between 130 and $310 \mathrm{~g}$, and the average weight was $226 \mathrm{~g}$. The average total number of spike and average total recording time of each experiment were 15,039 spikes and $607 \mathrm{~min}$, respectively. It was necessary to select the middle portion of each recorded dataset for analysis. The average values of time intervals for analysis, numbers of cycles of temperature change, and number of spike selected for analysis of these selected data were $214 \mathrm{~min}, 2$ cycles, and 5,433 spikes, respectively. The dataset gathered for analysis was composed of these selected data from each experiment. The total time interval for analysis and the total number of spike of this dataset were 1,713 minutes and 43,468 spikes, respectively. The numbers written in parentheses in the middle column of Table 1 represent the total number of cycles of temperature change for each experiment.
In each experiment, the temperature was maintained at room temperature for the first one hour. As shown in Table 2, average values of temperature and four AP parameters of burst-firing neurons were calculated using the selected dataset saved by intracellular recordings during maintaining at room temperature for 30 minutes; all data were selected after 5 to 10 minutes from temperature change onset. Because the standard errors of the values of these parameters were low, the bursting patterns of these experiments might be considered as regular while the temperatures were held constant at room temperature.

\section{Temperature dependence of AP parameters in burst-firing neurons}

We selected burst trains in a continuous time series from the intracellular recording data of experiment $\mathrm{A}$ during the fourth falling phase (from 440 to $487 \mathrm{~min}$ ) (Figure 2) out of the eight falling phases in temperature recorded during eight consecutive heating - cooling cycles: it was composed of 48 panels. Temperature and membrane potentials are represented as the upper and lower traces in Figure 2, respectively. These figures demonstrated that interburst interval, burst duration, and number of spike during burst decreased as temperature increased. Next, we extracted six burst signals (6 panels) among many burst signals to examine the temporal change of instantaneous ISI during burst at specific temperature; $30.0^{\circ} \mathrm{C}$ (at $440 \mathrm{~min}$ ), $26.9^{\circ} \mathrm{C}$ (at $454 \mathrm{~min}$ ), $23^{\circ} \mathrm{C}$ (at $464 \mathrm{~min}$ ), $21.3^{\circ} \mathrm{C}$ (at $468 \mathrm{~min}$ ), $19.1^{\circ} \mathrm{C}$ (at $474 \mathrm{~min}$ ), and $16.4^{\circ} \mathrm{C}$ (487 $\left.\mathrm{min}\right)$. As shown in Figure 3, ISI during burst versus time displayed parabolic pattern, suggesting that temperature-dependent bursting patterns are parabolic

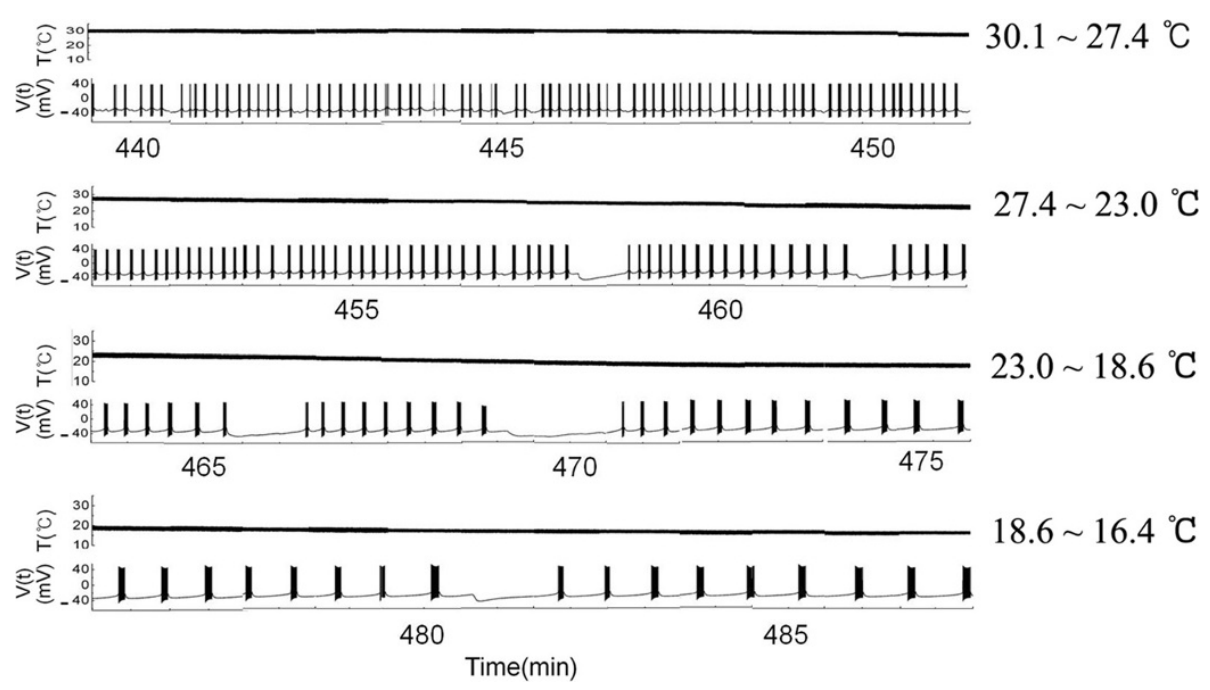

Figure 2 Continuous bursting patterns obtained from the dataset of intracellular recordings of experiment $\mathrm{A}$ during the 4 th falling phase (from $\mathbf{4 4 0}$ to $\mathbf{4 8 7}$ minutes) out of eight recorded falling phases. The temperature values of each panel is as follows; $30.1 \sim 27.4^{\circ} \mathrm{C}$ (top), $27.4 \sim 23^{\circ} \mathrm{C}$ ( $2 \mathrm{nd}$ from the top), $23 \sim 18.6^{\circ} \mathrm{C}$ (3rd from the top), and $18.6 \sim 16.4^{\circ} \mathrm{C}$ (bottom). As temperature decreased, the interburst interval, burst duration, and number of spike during burst increased. 


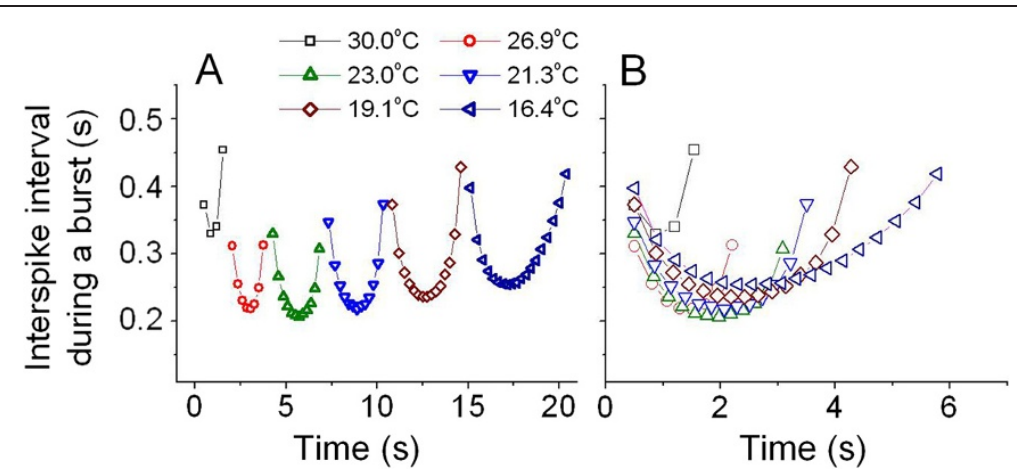

Figure 3 Plot of interspike intervals during a burst versus time. (A) Figures drawn by using data calculated from the burst shown on panels in Figure 2: parabolic shape. The values of temperature corresponding to the figures from the left to the right are $30.0^{\circ} \mathrm{C}, 26.9^{\circ} \mathrm{C}, 23.0^{\circ} \mathrm{C}, 21.3^{\circ} \mathrm{C}$, $19.1^{\circ} \mathrm{C}$, and $16.4^{\circ} \mathrm{C}$, sequentially. (B) The values of each figure are the same as those shown in (A): all the figures were shown with the same start time.

bursts characterized by lower spike frequency at the beginning and end of the burst. The analyzing dataset was composed of 1,713 files corresponding to the sum of each selected time interval for analysis as shown in the 4th column of the Table 1.

With the selected data shown in Table 1, the temperature-dependent properties of AP parameters were analyzed by using techniques similar to those described in Hyun et al. [1]. As shown in Figure 4A and C, all values of ISI and $\Delta \mathrm{t}_{\mathrm{r} 1}$ decreased and then increased as the temperature was raised, but frequency shown in Figure $4 \mathrm{~B}$ rose and then fell as the temperature increased. Figure $4 \mathrm{D}, \mathrm{E}$ and $\mathrm{G}$ show that the parameters $\Delta \mathrm{t}_{\mathrm{f} 2}, \Delta \mathrm{t}_{1 / 2}, \Delta \mathrm{t}_{\mathrm{r} 2}, \Delta \mathrm{t}_{\mathrm{f} 1}$, and $\mathrm{V}_{\mathrm{np} \text {,ave }}$ decreased as the temperature was raised with small standard errors for each value. On the other hand, the values of angles shown in Figure 4F increased as the temperature was raised, and the values of angle $\theta_{1}$ were larger than those of $\theta_{2}$. In addition, both $\mathrm{A}_{\mathrm{AP}}$, max and $\mathrm{A}_{\mathrm{AP}}$, ave shown in Figure $4 \mathrm{H}$ increased and then decreased as the temperature was raised. These temperature dependencies of $\mathrm{AP}$ parameters (except $\mathrm{A}_{\mathrm{AP}, \max }, \mathrm{A}_{\mathrm{AP}}$, ave, and angles) were similar to the case of those analyzed using a dataset obtained from beating cells: in that case, $\mathrm{A}_{\mathrm{AP} \text {,ave }}$ decreased as the temperature was raised between $16^{\circ} \mathrm{C}$

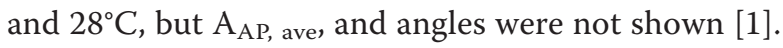

\section{Temperature dependence of bursting patterns in burst-firing neurons}

The values of six temperature-dependent burst parameters were averaged by using these selected dataset shown in Table 1. As shown in Figure 5A, B, and C respectively,

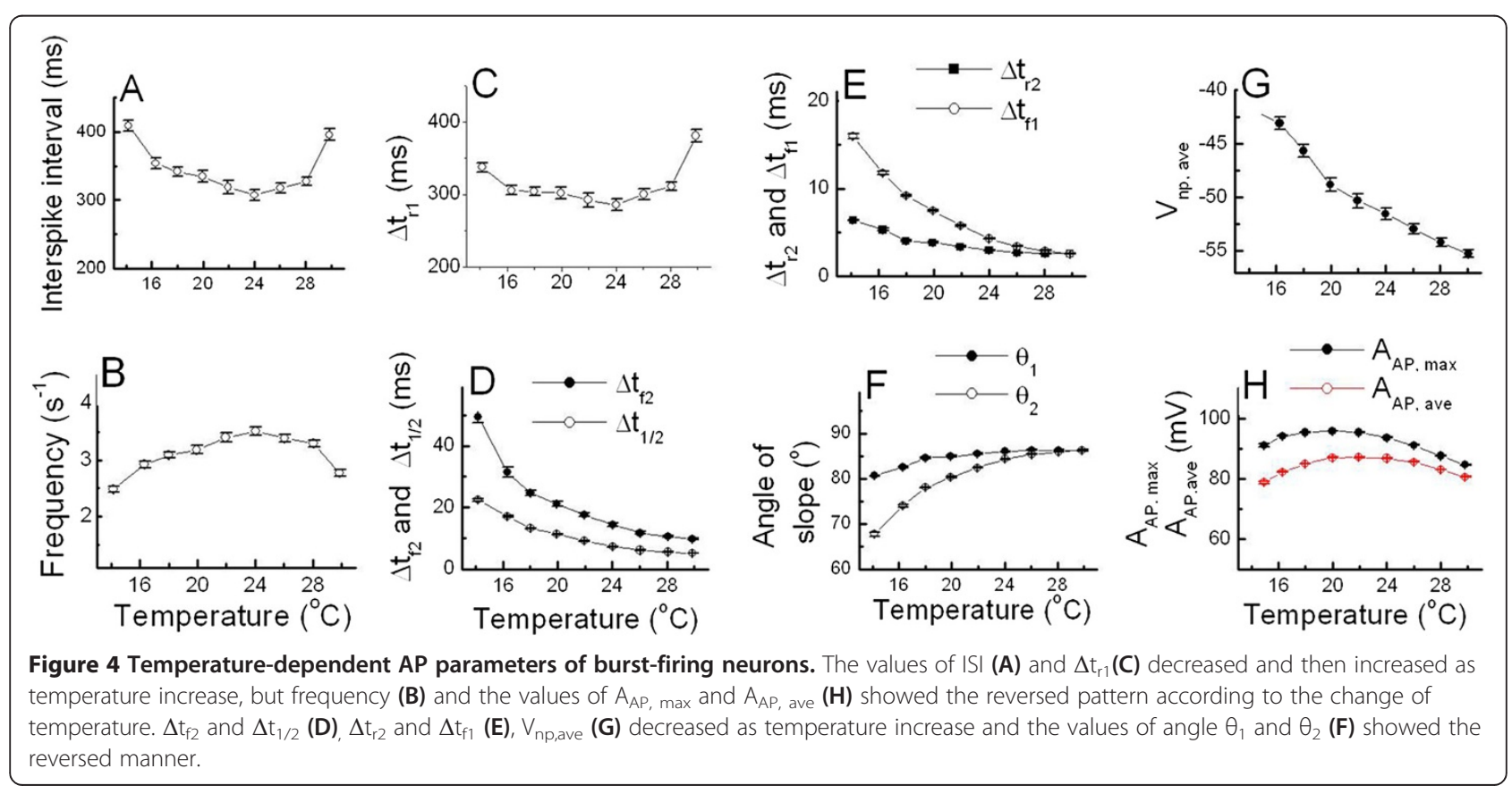



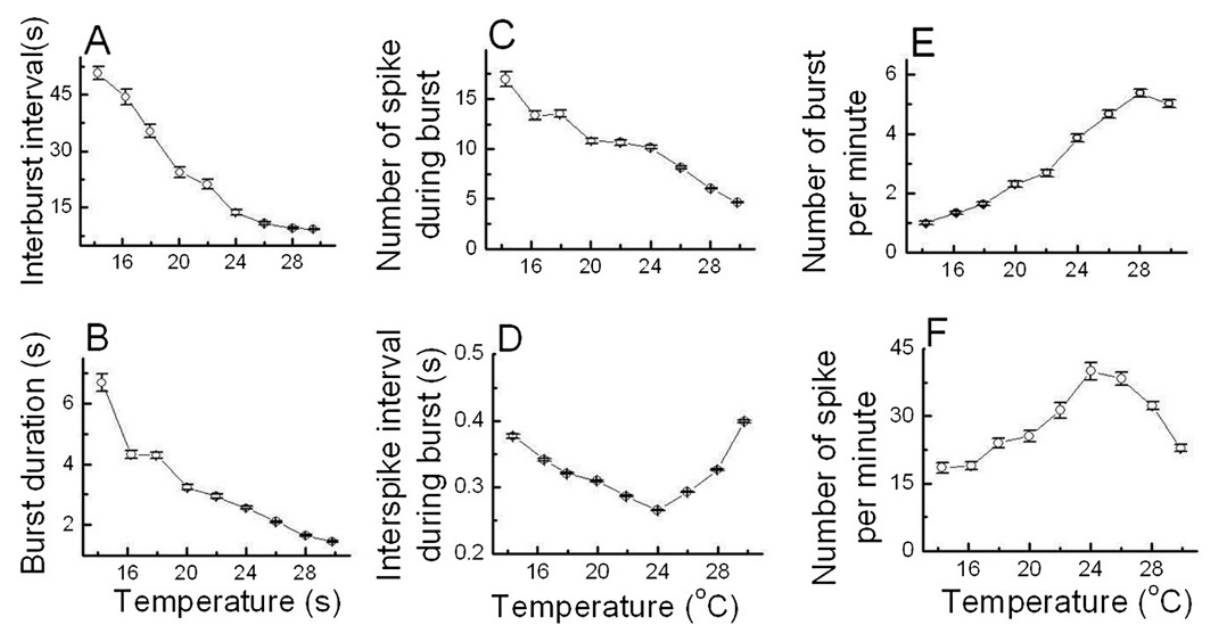

Figure 5 Temperature-dependent bursting patterns of burst-firing neurons. Interburst interval (A), burst duration (B), number of spike during burst (C) decreased as temperature increased. ISI during burst (D) showed a parabolic pattern which means that it decreased and then increased as temperature increased. Number of burst per minute $\mathbf{( E )}$ and number of spike per minute $\mathbf{( F )}$ increased and then decreased showing the reversed pattern of ISI during burst as temperature increased. The instantaneous ISI during a burst versus time firstly decreased and then increased showing the parabolic bursting pattern at each temperature ranging from $30^{\circ} \mathrm{C}$ to $16^{\circ} \mathrm{C}(\mathrm{G})$.

interburst interval, burst duration, and number of spike during burst decreased as temperature increased. ISI during burst shown in Figure 5D firstly decreased and then increased as temperature increased. In contrast, the numbers of burst per minute and of spike per minute shown in Figure 5E and $F$ respectively increased and then decreased as the temperature was raised.

However, since these six burst parameters were not independent parameters, some equations representing an interrelationship between these parameters of burst-firing neurons could be driven; number of spike during burst = (burst duration)/(inter spike interval during burst), number of spike per minute $=($ number of spike during burst $) \times$ (number of burst per minute), and number of burst per minute $=60 /$ (interburst interval + burst duration).

The values of these six temperature-dependent burst parameters during lowering the temperature $(\bullet)$ and raising the temperature (o) are shown in Figure 6. In the cases of interburst interval, burst duration, number of spike during burst, and ISI during burst shown in Figure 6A, B, C, and $D$ respectively, there were no significant differences in these parameter values between the cooling-off and heat periods, which could be considered that there were reproducible properties of temperature dependencies in these burst parameters. Moreover, the number of burst per minute and spike per minute during heating shown in Figure $6 \mathrm{E}$ and $\mathrm{F}$ were slightly larger than those during cooling between $19^{\circ} \mathrm{C}$ and $25^{\circ} \mathrm{C}$. However, it might be thought that the reproducible property of temperaturedependent changes in bursting patterns could not be undermined by these. It is because the values of the experimental percentage error of interspike interval during burst were between $0.1 \%$ and $14.1 \%$; experimental percentage error $\equiv 100 \% \times$ | value of bursting parameter during heating (cooling) - average value of bursting parameter |/ average value of bursting parameter.

Thus, each mean value of functional forms of reproducible temperature-dependent bursting parameters in Figures 5 and 6 could be calculated by using these dataset and the computer program we designed. It was shown that these six bursting parameters changed in response to temperature variation, but the mechanism underlying these correlations remains unverified. So, it was suggested that performing computational simulations of these phenomena by using a modified Plant model which were composed of equations with temperature-dependent scaling factors was necessary to mathematically clarify the temperature-dependent changes of bursting patterns in burst-firing neurons.

\section{Simulation of temperature-dependent bursting patterns}

In order to simulate various temperature-dependent spiking patterns of bursting pacemaker neuron, we set up nonlinear differential equations by modifying the Plant model [15] with temperature-dependent scaling factors [25-27]. The Plant model studied by Rinzel and Lee was designed to assess parabolic bursters by analyzing the fast and slow processes to show how spike activities were generated by their mutual interaction [16].

The cell membrane of modified Plant model contains sodium channels carrying a fast sodium current, $\mathrm{I}_{\mathrm{Na}}$, and potassium channels underlying a fast potassium current, $\mathrm{I}_{\mathrm{K}}$. The slow processes include the slow inward calcium current, $\mathrm{I}_{\mathrm{Ca}}$, and the slow changes in intracellular free calcium concentration, $\mathrm{Ca}$. The accumulation of calcium turns on outward calcium-activated potassium current, $\mathrm{I}_{\mathrm{K}(\mathrm{Ca})}$, and undermines the slow inward calcium current, 
and finally brings to an end of bursting activity. This system also contains a leak current, $\mathrm{I}_{\mathrm{L}}$.

$$
\begin{aligned}
-\mathrm{C}_{\mathrm{m}} \frac{\mathrm{dV}}{\mathrm{dt}} & =\rho(\mathrm{T})\left(\mathrm{I}_{\mathrm{Na}}+\mathrm{I}_{\mathrm{Ca}}+\mathrm{I}_{\mathrm{K}}+\mathrm{I}_{\mathrm{K}(\mathrm{Ca})}\right)+\mathrm{I}_{\mathrm{L}} \\
& =\rho(\mathrm{T})\left\{\overline{\mathrm{g}}_{\mathrm{Na}} \cdot \mathrm{m}_{\infty}^{3}(\mathrm{~V}) \cdot \mathrm{h} \cdot\left(\mathrm{V}-\mathrm{V}_{\mathrm{Na}}\right)+\overline{\mathrm{g}}_{\mathrm{Ca}} \cdot \mathrm{X} \cdot\left(\mathrm{V}-\mathrm{V}_{\mathrm{Ca}}\right)\right. \\
& +\left(\overline{\mathrm{g}}_{\mathrm{K}} \cdot \mathrm{n}^{4}+\overline{\mathrm{g}}_{\mathrm{K}-\mathrm{Ca}} \frac{\mathrm{Ca}}{0.2+\mathrm{Ca}}\right) \cdot\left(\mathrm{V}-\mathrm{V}_{\mathrm{K}}\right)+\overline{\mathrm{g}}_{\mathrm{L}} \cdot\left(\mathrm{V}-\mathrm{V}_{\mathrm{L}}\right)
\end{aligned}
$$

$$
\begin{aligned}
\frac{\mathrm{dh}}{\mathrm{dt}} & =\phi(\mathrm{T}) \cdot \lambda \frac{\left[\mathrm{h}_{\infty}(\mathrm{V})-\mathrm{h}\right]}{\mathrm{T}_{\mathrm{h}}(\mathrm{V})}, \\
\frac{\mathrm{dX}}{\mathrm{dt}} & =\phi(\mathrm{T}) \frac{\mathrm{X}_{\infty}(\mathrm{V})-\mathrm{X}}{\mathrm{\tau X}}, \\
\frac{\mathrm{dn}}{\mathrm{dt}} & =\phi(\mathrm{T}) \cdot \lambda \frac{\left[\mathrm{n}_{\infty}(\mathrm{V})-\mathrm{n}\right]}{\tau_{\mathrm{n}}(\mathrm{V})}, \\
\frac{\mathrm{dCa}}{\mathrm{dt}} & =\rho \cdot\left[\mathrm{K}_{\mathrm{c}} \cdot \mathrm{X} \cdot\left(\mathrm{V}_{\mathrm{Ca}}-\mathrm{V}\right)-\mathrm{Ca}\right],
\end{aligned}
$$

Where

$$
\begin{aligned}
& \mathrm{m}_{\infty}(\mathrm{V})=\frac{\mu \mathrm{m} \frac{50-\alpha \mathrm{V}-\beta}{\left(\frac{50-\alpha \mathrm{V}-\beta}{10}\right)}-1}{\mathrm{e}^{\left(\frac{25-\alpha \mathrm{V}-\beta}{18}\right)}}, \\
& \mathrm{h}_{\infty}(\mathrm{V})=\frac{\mathrm{e}^{\left(\frac{50-\alpha \mathrm{V}-\beta}{10}\right)}+4 \mathrm{e}_{-1}}{\left.\mu_{\mathrm{h}} \mathrm{e}^{\left(\frac{25-\alpha \mathrm{V}-\beta}{20}\right)}+\frac{25-\alpha \mathrm{V}-\beta}{20}\right)} \frac{\mathrm{e}^{\left(\frac{55-\alpha \mathrm{V}-\beta}{10}\right)}}{\mathrm{e}^{\left(\frac{25}{10}\right)}} \\
& \mathrm{X}_{\infty}(\mathrm{V})=\frac{1}{1+\mathrm{e}^{\gamma(\delta-V)},}
\end{aligned}
$$

and

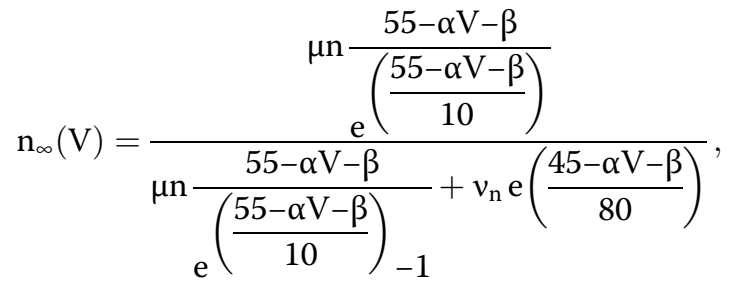

$$
\begin{aligned}
& \tau_{\mathrm{h}}(\mathrm{V})=\frac{1}{\mu_{\mathrm{h}} \mathrm{e}^{\left(\frac{25-\alpha \mathrm{V}-\beta}{20}\right)}+\frac{1}{\mathrm{e}^{\left(\frac{55-\alpha \mathrm{V}-\beta}{10}\right)}+1}},
\end{aligned}
$$

and

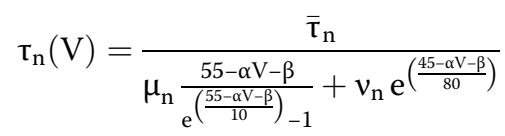

Where $\overline{\mathrm{g}}_{\mathrm{Na}}, \overline{\mathrm{g}}_{\mathrm{Ca}}, \overline{\mathrm{g}}_{\mathrm{K}}$, and $\overline{\mathrm{g}}_{\mathrm{L}}$ are maximal conductances for the $\mathrm{Na}^{+}, \mathrm{Ca}^{2+}, \mathrm{K}^{+}$, and $\mathrm{Cl}^{-}$currents, respectively, and $\mathrm{V}_{\mathrm{Na}}, \mathrm{V}_{\mathrm{Ca}}, \mathrm{V}_{\mathrm{K}}$, and $\mathrm{V}_{\mathrm{L}}$ are the reversal potentials for the respective currents: $\overline{\mathrm{g}}_{\mathrm{K}(\mathrm{Ca})}$ is maximal conductance for calcium-activated potassium current. Here, voltage, $\mathrm{V}$ indicates membrane potential $(\mathrm{mV})$.

The voltage-dependent activation and inactivation variables for sodium channels are $m$ and $h$ respectively, and the activation variable for potassium channels is $n$. A slowly activating conductance for calcium current is denoted by $x$, and a slow change in intracellular free calcium concentration $\mathrm{Ca}$, is treated as parameters. The maximal relaxation time constants of $h$ and $n$ are defined as $\frac{1}{\lambda}$. It is taken that $\rho^{-1}$ is an estimate for the time-constant of the Ca-equation. The temperaturedependent scaling factors, $\rho(\mathrm{T})$ and $\phi(\mathrm{T})$, are defined as $\rho(T) \equiv 1.3^{\frac{T-T_{0}}{10^{\circ} \mathrm{C}}}$ and $\phi(T) \equiv 3^{\frac{T-T_{0}}{10^{\circ} \mathrm{C}}}$, respectively [25]. The steady-state values of activation or inactivation variables $\mathrm{m}_{\infty}, \mathrm{h}_{\infty}, \mathrm{X}_{\infty}$, and $\mathrm{n}_{\infty}$ are functions of voltage. The relaxation time constants are represented by $\tau_{h}, \tau_{x}$, and $\tau_{n}$.

\section{Comparison of experimental and simulation results}

In order to obtain good computer simulation of temperature-dependent bursting patterns generated respectively by these eight bursting pacemaker neurons, it was necessary to select three good data files of each experiment. The figures drawn by using data files selected during the same rising (or falling) phase of temperature change from dataset of experiment $\mathrm{A}$ at temperatures below $20^{\circ} \mathrm{C}$, between $20^{\circ} \mathrm{C}$ and $25^{\circ} \mathrm{C}$, above $25^{\circ} \mathrm{C}$, were expressed by symbols L1, M1, H1, respectively, shown on Figure 7. Similarly, the figures shown by using data files selected from datasets of experiments $\mathrm{B}-\mathrm{H}$ at the same temperature ranges were symbolized by L2- L8, M2 - M8, and H2 - H8, respectively, shown on Figure 7.

Then, it was necessary to describe how to draw three figures shown on the panels L1, M1, and H1 in Figure 7. Firstly, temperature values shown on these figures should be substituted for $\mathrm{T}$ in the temperature-dependent scaling factors, $\rho(T)$ and $\phi(T)$ involved in modified Plant model. Secondly, computer simulation should be carried out until percentage errors of all parameters had to be calculated below $50 \%$ : the results of these calculations were shown at first three rows in Table 3. However, percentage error could be defined with the following formula shown below:

Finally, numerical values of each of the 24 parameters involved in equations (1) to (4) would be fixed: $C_{m}=1$ $\mu \mathrm{F} / \mathrm{cm}^{2}, \overline{\mathrm{g}}_{\mathrm{KCa}}=0.018 \mathrm{mmho} / \mathrm{cm}^{2}, \overline{\mathrm{g}}_{\mathrm{Na}}=4.0 \mathrm{mmho} / \mathrm{cm}^{2}$, 

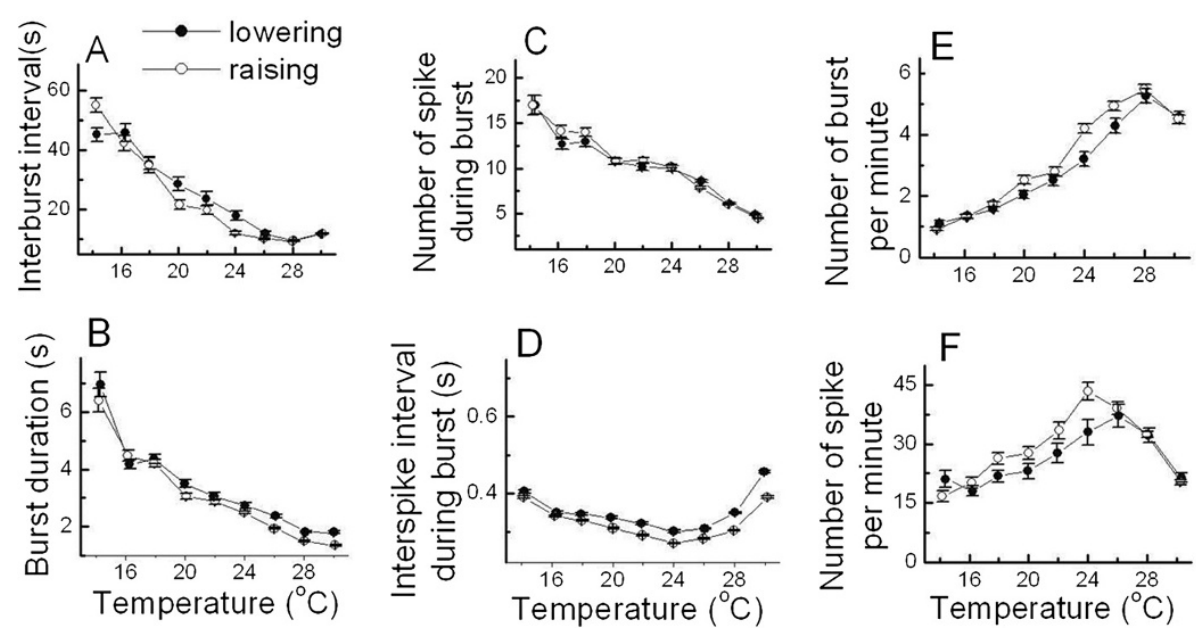

Figure 6 Reproducible temperature-dependent bursting patterns of burst-firing neurons while decreasing $(\bullet)$ and increasing the temperature ( $\circ)$. There is no remarkable difference in each AP parameters when compared the values according to temperature between the cooling-off and heating period which means the reproducible properties of temperature-dependent burst parameters (A to F).

Percentage error $\equiv \frac{\mid \text { the average value of the simulated data } \text {-the average value of the experimental data } \mid}{\text { the average value of the experimental data }} \times 100 \%$

$\overline{\mathrm{g}}_{\mathrm{Ca}}=0.007 \mathrm{mmho} / \mathrm{cm}^{2}, \quad \overline{\mathrm{g}}_{\mathrm{K}}=0.60 \mathrm{mmho} / \mathrm{cm}^{2}, \overline{\mathrm{g}}_{\mathrm{L}}=$ $0.017 \mathrm{mmho} / \mathrm{cm}^{2}, \mathrm{~V}_{\mathrm{Na}}=40 \mathrm{mV}, \mathrm{V}_{\mathrm{Ca}}=140 \mathrm{mV}, \mathrm{V}_{\mathrm{K}}=-75 \mathrm{mV}$, $\mathrm{V}_{\mathrm{L}}=-40 \mathrm{mV}, \lambda=0.18, \rho=0.000074 \mathrm{~ms}^{-1}, \mathrm{~T}_{\mathrm{X}}=1,500$, $\mathrm{K}_{\mathrm{c}}=0.0275 \mathrm{mV}^{-1}, \alpha=127 / 105, \quad \beta=8265 / 105, \quad \gamma=0.3$, $\delta=-18, \mu_{\mathrm{m}}=0.1, \mu_{\mathrm{h}}=0.08, \mu_{\mathrm{n}}=0.016, v_{\mathrm{n}}=0.1, \overline{\mathrm{\tau}}_{\mathrm{n}}=1$, $\mathrm{T}_{0}=23.0^{\circ} \mathrm{C}$. Here, we took a value of $23^{\circ} \mathrm{C}$ as the reference temperature $\mathrm{T}_{0}$ because bursts are usually activated from $22^{\circ} \mathrm{C}$ to $25^{\circ} \mathrm{C}$, and this represented the middle value of temperature range of the experiment $\mathrm{A}$; from $16.0^{\circ} \mathrm{C}$ to $30.0^{\circ} \mathrm{C}$.

To simulate the other figures shown in Figure 7, it was necessary to fix the same numerical values of each of the 22 parameters as those used in experiment $\mathrm{A}$, except the values of $\rho$ and $\tau_{x}$. And then, computer simulation should be carried out by changing parameter values $\rho$ and $\tau_{x}$ until percentage errors of all parameters had to be calculated below 50\%: interburst interval, burst duration, and number of spike per burst were increased (number of burst per minute decreased) as $\rho$, and $\tau_{x}$ increased. The results of these calculations were shown from 4th row to the last row in Table 3: the values of all calculated percentage errors were between 0 and $47.7 \%$. Here, the results about the number of spike per minute among burst parameters was excluded from Table 3, because all percentage errors in the number of burst per minute were 0.0 and then the values of number of spike during burst would be the same as the values of number of spike per minute.

The results of computer simulation with the values of temperature shown on each panel in Figure 7 are represented as the time series of bursting activity. Although the results of simulation (red solid line) of AP amplitude were not completely optimal, simulation data for number of burst per minute, number of spike during burst, inter-burst interval, burst duration, and interspike interval during burst were well reflected by modified Plant model when these simulation results were compared to the experimental results (blue dotted line).

Therefore, analysis and simulation of the experimental data by our equation model might be helpful for understanding the mechanisms underlying the change of temperature-dependent bursting activity in neurons.

\section{Discussion}

In the previous study we analyzed the temperaturedependent change of 14 AP parameters (such as the AP amplitude, membrane potential at the positive peak, ISI, first half and last half of the temperature rising phase, first half and last half of the temperature falling phase, absolute value of the membrane potential at negative peak, absolute value of the maximum slope of the AP during the temperature rising and falling phases, and spiking frequency) in Aplysia neurons [1]. With these findings, in this study we tried to examine the temperature-dependent change of bursting patterns in pacemaker neuron at abdominal ganglion of Aplysia juliana. Furthermore, we attempted to identify the mechanism underlying the temperature dependence of busting by developing an equation model predicting neuronal electrophysiological activity with a function of temperature. 


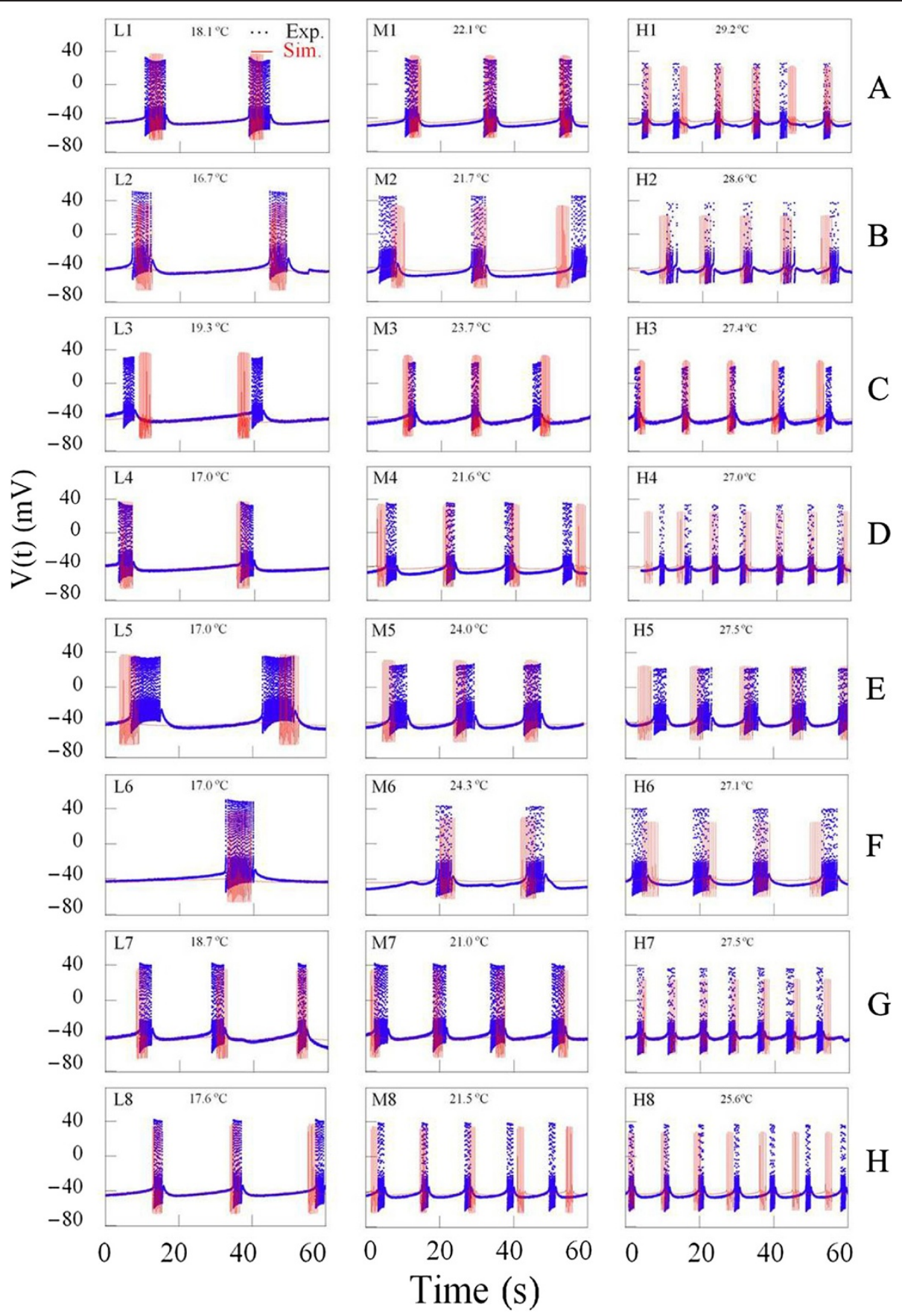

Figure 7 Time series of bursting activity drawn by using the data for the experiments from $\mathrm{A}$ to $\mathrm{H}$ and computer simulations (A to $\mathbf{H}$ from top to bottom panel). The results of experiments (blue, dotted line) and computer simulation (red, solid line) are represented as the activity with the same corresponding temperatures shown on each panel. The figures shown by using data files selected from datasets of experiments $\mathbf{A}-\mathbf{H}$ (from top to bottom panel) were symbolized by $\mathrm{L} 1-\mathrm{L} 8, \mathrm{M} 1-\mathrm{M} 8$, and $\mathrm{H} 1-\mathrm{H}$, at the temperature ranges below $20^{\circ} \mathrm{C}$, between $20^{\circ} \mathrm{C}$ and $25^{\circ} \mathrm{C}$, above $25^{\circ} \mathrm{C}$, respectively. Computer simulations should be carried out until percentage errors of all parameters had to be calculated below $50 \%$.

\section{Temperature-dependent change of bursting patterns}

Firstly we conducted real experiments with bursting pacemaker neurons in order to explore the functional relation between temperature and bursting patterns as well as AP parameters. We examined the temperature-dependent activity of bursting pacemaker neurons during several consecutive heating-cooling cycles. We tested the temperature dependencies of AP parameters in bursting pacemaker neurons in the temperature range of $16-30^{\circ} \mathrm{C}$. The temperature-dependent properties of AP parameters 
Table 3 Comparison of experimental and simulation results

\begin{tabular}{|c|c|c|c|c|c|c|c|c|c|c|c|c|c|c|c|c|c|c|}
\hline \multirow[t]{3}{*}{ Exp } & \multirow{2}{*}{\multicolumn{3}{|c|}{$\begin{array}{l}\text { Parameters of } \\
\text { modified Plant model }\end{array}$}} & \multicolumn{15}{|c|}{ Burst parameters and percent error } \\
\hline & & & & \multicolumn{3}{|c|}{$\begin{array}{l}\text { Number of burst } \\
\text { per minute }\end{array}$} & \multicolumn{3}{|c|}{$\begin{array}{l}\text { Number of spike } \\
\text { during burst }\end{array}$} & \multicolumn{3}{|c|}{ Interburst interval (s) } & \multicolumn{3}{|c|}{ Burst duration (s) } & \multicolumn{3}{|c|}{$\begin{array}{l}\text { Interspike interval } \\
\text { during burst (ms) }\end{array}$} \\
\hline & $\rho$ & $\mathbf{\tau}_{x}$ & $\mathrm{~T}\left({ }^{\circ} \mathrm{C}\right)$ & Ex & $\mathrm{Si}$ & Err (\%) & Ex & $\mathrm{Si}$ & Err (\%) & Ex & $\mathrm{Si}$ & Err (\%) & Ex & $\mathrm{Si}$ & Err (\%) & Ex & $\mathrm{Si}$ & Err (\%) \\
\hline \multirow[t]{3}{*}{$A$} & 0.000074 & 1500 & 18.1 & 20 & 20 & 0.0 & 21.0 & 13.0 & 38.0 & 22.5 & 23.5 & 4.4 & 5.2 & 3.4 & 34.6 & 247 & 261 & 5.6 \\
\hline & & & 22.1 & 3.0 & 3.0 & 0.0 & 16.0 & 12.0 & 25.0 & 15.5 & 17.3 & 11.6 & 3.2 & 3.1 & 3.1 & 200 & 258 & 29.0 \\
\hline & & & 29.2 & 6.0 & 6.0 & 0.0 & 5.0 & 7.0 & 40.0 & 7.6 & 7.8 & 2.6 & 1.3 & 1.9 & 46.1 & 260 & 271 & 4.2 \\
\hline \multirow[t]{3}{*}{$\nabla$} & 0.00015 & 9000 & 16.7 & 20 & 20 & 0.0 & 11.0 & 13.0 & 18.1 & 32.0 & 31.6 & 1.2 & 4.8 & 4.2 & 12.5 & 436 & 323 & 25.9 \\
\hline & & & 21.7 & 3.0 & 3.0 & 0.0 & 11.0 & 11.0 & 0.0 & 16.0 & 18.9 & 18.1 & 3.9 & 3.2 & 17.9 & 354 & 290 & 18.0 \\
\hline & & & 28.6 & 5.0 & 5.0 & 0.0 & 5.0 & 7.0 & 40.0 & 8.2 & 8.0 & 2.4 & 2.3 & 2.8 & 21.7 & 460 & 400 & 13.0 \\
\hline \multirow[t]{3}{*}{ C } & 0.00006 & 790 & 19.3 & 20 & 20 & 0.0 & 11.0 & 13.0 & 18.1 & 31.7 & 23.3 & 26.4 & 2.6 & 3.2 & 23.0 & 236 & 246 & 4.2 \\
\hline & & & 23.7 & 3.0 & 3.0 & 0.0 & 8.0 & 11.0 & 37.5 & 13.8 & 15.9 & 15.2 & 1.9 & 2.4 & 26.3 & 237 & 218 & 8.0 \\
\hline & & & 27.4 & 5.0 & 5.0 & 0.0 & 7.0 & 8.0 & 14.2 & 9.6 & 10.1 & 5.2 & 1.2 & 1.7 & 41.6 & 171 & 212 & 23.9 \\
\hline & 0.00028 & 13000 & 17.0 & 20 & 20 & 0.0 & 13.0 & 10.0 & 23.0 & 29.0 & 28.0 & 3.4 & 3.4 & 3.2 & 5.8 & 261 & 320 & 22.6 \\
\hline & & & 21.6 & 4.0 & 4.0 & 0.0 & 9.3 & 8.0 & 13.9 & 13.0 & 15.2 & 16.9 & 2.2 & 2.5 & 13.6 & 236 & 312 & 32.2 \\
\hline & & & 27.0 & 7.0 & 7.0 & 0.0 & 4.8 & 5.0 & 4.1 & 6.4 & 6.9 & 7.8 & 1.3 & 1.9 & 46.1 & 270 & 380 & 40.7 \\
\hline \multirow[t]{3}{*}{$E$} & 0.00015 & 15000 & 17.0 & 20 & 20 & 0.0 & 27.0 & 15.0 & 44.4 & 27.9 & 38.8 & 39.0 & 7.7 & 4.9 & 36.3 & 285 & 326 & 14.3 \\
\hline & & & 24.0 & 3.0 & 3.0 & 0.0 & 18.0 & 11.0 & 38.8 & 11.6 & 16.5 & 42.2 & 4.5 & 3.5 & 22.2 & 250 & 318 & 27.2 \\
\hline & & & 27.5 & 5.0 & 5.0 & 0.0 & 12.5 & 8.2 & 34.4 & 8.8 & 10.4 & 18.1 & 3.4 & 3.3 & 2.9 & 272 & 402 & 47.7 \\
\hline \multirow[t]{3}{*}{$F$} & 0.00016 & 27000 & 17.0 & 1.0 & 1.0 & 0.0 & 18.0 & 18.0 & 0.0 & (69.3) & $(50.9)$ & $(26.5)$ & 7.3 & 6.0 & 17.8 & 405 & 333 & 17.7 \\
\hline & & & 24.3 & 20 & 20 & 0.0 & 10.0 & 11.0 & 10.0 & 19.7 & 18 & 8.6 & 3.9 & 3.9 & 0.0 & 390 & 354 & 9.2 \\
\hline & & & 27.1 & 4.0 & 4.0 & 0.0 & 12.6 & 10.0 & 20.6 & 10.4 & 11.5 & 10.5 & 3.7 & 3.8 & 2.7 & 293 & 380 & 29.6 \\
\hline \multirow[t]{3}{*}{ G } & 0.00022 & 7000 & 18.7 & 3.0 & 3.0 & 0.0 & 10.5 & 9.0 & 14.2 & 15.3 & 18.8 & 22.8 & 3.0 & 2.7 & 10.0 & 285 & 300 & 5.2 \\
\hline & & & 21.0 & 4.0 & 4.0 & 0.0 & 13.3 & 8.0 & 39.8 & 10.0 & 14.4 & 44 & 3.3 & 2.5 & 24.2 & 248 & 312 & 25.8 \\
\hline & & & 27.5 & 7.0 & 7.0 & 0.0 & 6.0 & 5.0 & 16.6 & 5.9 & 6.6 & 11.8 & 1.5 & 1.6 & 6.6 & 250 & 320 & 28.0 \\
\hline \multirow[t]{3}{*}{$\mathrm{H}$} & 0.00028 & 7000 & 17.6 & 3.0 & 3.0 & 0.0 & 7.0 & 8.0 & 14.2 & 17.6 & 18.7 & 6.2 & 2.1 & 2.5 & 19.0 & 300 & 312 & 4.0 \\
\hline & & & 21.5 & 5.0 & 5.0 & 0.0 & 6.0 & 6.0 & 0.0 & 8.8 & 11.6 & 31.8 & 1.3 & 1.6 & 23.0 & 216 & 266 & 23.1 \\
\hline & & & 25.6 & 7.0 & 7.0 & 0.0 & 5.0 & 5.0 & 0.0 & 7.4 & 7.3 & 1.3 & 1.0 & 1.4 & 40.0 & 200 & 280 & 40.0 \\
\hline
\end{tabular}

(): 2-minute average value, Exp \& Ex: experimental value.

Si: simulation parameter value, Err. Percent error $=\frac{\mid \text { the average of the experimental data- the average of the simulated data } \mid}{\text { the average of the experimental data }} \times 100 \%$. Computer simulation should be carried out by changing parameter values $\rho$ and $\tau_{x}$, until percentage errors of all parameters had to be calculated below $50 \%$.

were analyzed with the selected data shown in Table 1 by using techniques similar to those described in Hyun et al. [1].

The values of inter-burst interval, burst duration, and number of spike during burst decreased as the temperature increased, and it was possible to confirm functional properties of temperature dependencies in six burst parameters. When compared to data reported by other research group, Fletcher and Ram analyzed changes of AP parameters of burst-firing neurons during heating by investigating Aplysia R15 pacemaker neuron activity in the temperature range of $23-37^{\circ} \mathrm{C}$; they found that interburst interval, burst duration, and number of spike per burst all decreased within the temperature range of 23 to $32^{\circ} \mathrm{C}$ [21]. We found that our data are consistent with results reported by Fletcher and Ram [21] within the temperature range of 23 to $30^{\circ} \mathrm{C}$. Furthermore, the present study revealed that the values of ISI and $\Delta \mathrm{t}_{\mathrm{r} 1}$ decreased and then increased, frequency increased and then decreased, and the parameters $\Delta \mathrm{t}_{\mathrm{f} 2}, \Delta \mathrm{t}_{1 / 2}, \Delta \mathrm{t}_{\mathrm{r} 2}, \Delta \mathrm{tf}_{1}$, and $\mathrm{V}_{\mathrm{np}}$ all decreased as the temperature was raised. These results were similar to those shown in previously published paper [1]. Fletcher and Ram also showed that intra-burst spike broadening and spike height decreased as temperature increased [21]. These results were also in good accordance with our experimental results within the temperature range of 23 to $30^{\circ} \mathrm{C}$. Because $\Delta \mathrm{t}{ }_{1 / 2}$ and $\mathrm{A}_{\mathrm{AP} \text {,ave }}$ decreased as temperature increased in the temperature range of 23 to $30^{\circ} \mathrm{C}$, as shown in Figure $4 \mathrm{D}$ and $\mathrm{H}$ : two parameters, spike-broadening and spike height, could be compared with two AP parameters, $\Delta \mathrm{t}_{\mathrm{AP}, 1 / 2}$ and $\mathrm{A}_{\mathrm{AP} \text {,ave, respect- }}$ ively. Moreover the present study generated quantitative data regarding the temperature-dependent properties of the other three AP parameters of burst-firing neurons 
(ISI during burst, number of burst per minute, and number of spike per minute) and nine other AP parameters (ISI, $\Delta \mathrm{t}_{\mathrm{r} 1}, \Delta \mathrm{t}_{\mathrm{r} 2}, \Delta \mathrm{t}_{\mathrm{f} 1}, \Delta \mathrm{t}_{\mathrm{f} 2}, \theta_{1}, \theta 2, \mathrm{~V}_{\mathrm{np}}$, and $\mathrm{A}_{\mathrm{AP}, \max }$ ).

\section{Mechanism underlying the temperature dependence of busting: choice of the model}

Numerous revised model of bursting in R15 [17-19,28] have been developed since the mid-1980s. Canavier et al. [17] developed the model of bursting in R15 with 10 currents and 11 static variables; 10 currents (the fast $\mathrm{Na}^{+}$-current $\mathrm{I}_{\mathrm{Na}}$, the fast $\mathrm{Ca}^{2+}$-current $\mathrm{I}_{\mathrm{Ca}}$, the delayed rectifier $\mathrm{K}^{+}$-current $\mathrm{I}_{\mathrm{K}}$, the slow inward $\mathrm{Ca}^{2+}$-current $\mathrm{I}_{\mathrm{SI}}$, the nonspecific cation current $I_{N S}$, the anomalous rectifier current $I_{R}$, the leak current $I_{L}, K^{+}$-current $I_{K}$, the $\mathrm{Na}^{+}-\mathrm{Ca}^{2+}$ exchanger current $\mathrm{I}_{\mathrm{NaCa}}$, the $\mathrm{Na}^{+}-\mathrm{K}^{+}$pump current $\mathrm{I}_{\mathrm{NaK}}$, and the $\mathrm{Ca}^{2+}$ pump current $\mathrm{I}_{\mathrm{CaP}}$ ), and 11 static variables (membrane potential $\mathrm{V}$, intracellular concentration of $\mathrm{Ca}^{2+}[\mathrm{Ca}]_{\mathrm{i}}$, the occupancy of the intracellular $\mathrm{Ca}^{2+}$-buffer $\mathrm{O}_{c}$, and eight voltage-dependent state-variables (m, h, d, f, n, l, s, b)). The parabolic bursting pattern results from two competing processes, the slow voltage-dependent activation of the slow inward $\mathrm{Ca}^{2+}$-current $\left(\mathrm{I}_{\mathrm{SI}}\right)$, and the still more slower calciumdependent inactivation of this same current. Butera et al. [19] also developed the models of bursting in R15 with 10 currents and 12 static variables; 10 currents (the fast $\mathrm{Na}^{+}$-current $\mathrm{I}_{\mathrm{Na}}$, the fast $\mathrm{Ca}^{2+}$-current $\mathrm{I}_{\mathrm{Ca}}$, the delayed rectifier $\mathrm{K}^{+}$-current $\mathrm{I}_{\mathrm{K}}$, the slow inward $\mathrm{C}^{2+}$-current $\mathrm{I}_{\mathrm{SI}}$, the nonspecific cation current $\mathrm{I}_{\mathrm{NS}}$, the anomalous rectifier current $I_{R}$, the leak current $I_{L}, K^{+}$-current $I_{K}$, the $\mathrm{Na}^{+}-\mathrm{Ca}^{2+}$ exchanger current $\mathrm{I}_{\mathrm{NaCa}}$, the $\mathrm{Na}^{+}-\mathrm{K}^{+}$pump current $\mathrm{I}_{\mathrm{NaK}}$, and the $\mathrm{Ca}^{2+}$ pump current $\mathrm{I}_{\mathrm{CaP}}$ ), and 12 static variables (membrane potential $\mathrm{V}$, intracellular concentration of $\mathrm{Ca}^{2+}\left[\mathrm{Ca}^{2+}\right]_{\mathrm{i}}$, intracellular concentration of cAMP [CAMP], the occupancy of the intracellular $\mathrm{Ca}^{2+}$-buffer $\mathrm{O}_{c}$, and eight voltage-dependent statevariables $(\mathrm{m}, \mathrm{h}, \mathrm{d}, \mathrm{f}, \mathrm{n}, \mathrm{l}, \mathrm{s}, \mathrm{b}))$. The slow inward $\mathrm{Ca}^{2+}$ current $\left(\mathrm{I}_{\mathrm{SI}}\right)$ in this model is the key current responsible for leading to bursting phenomena.

In addition to these models, Bertram [18,29] developed a mathematical model of bursting neuron R15 including 8 currents and 11 static variables; 8 currents (excitatory sodium current $\mathrm{I}_{\mathrm{Na}}$, excitatory calcium current $\mathrm{I}_{\mathrm{Ca}}$, inhibitory potassium current $\mathrm{I}_{\mathrm{K} 1}$ and $\mathrm{I}_{\mathrm{K} 2}$, small leakage current $\mathrm{I}_{\mathrm{L}}$, calcium current which initiate the burst $\mathrm{I}_{\mathrm{NSR}}$, and cation-nonspecific current $\mathrm{I}_{\mathrm{D}}$, and a potassium current which is activated only near the potassium equilibrium potential $\mathrm{I}_{\mathrm{R}^{\prime}}$ ) and 11 static variables (membrane potential V, intracellular concentration of $\mathrm{Ca}^{2+} \mathrm{c}$, and nine voltage-dependent state-variables $(\mathrm{m}, \mathrm{h}, \mathrm{n}, \mathrm{j}, \mathrm{q}, \mathrm{y}, \mu, \mathrm{r}, \mathrm{x})$ ). Two subthreshold burst currents, the calcium current which initiate the burst $\mathrm{I}_{\mathrm{NSR}}$ and the cation-nonspecific current $\mathrm{I}_{\mathrm{D}}$, induce the busting oscillation.
To mathematically clarify the temperature-dependent changes of bursting patterns in burst-firing neurons, it was suggested to perform computational simulations of these phenomena by using a proper model composed of equations with temperature-dependent scaling factors.

We have tried to conduct computational simulations by using modified models: in modifying the models that were developed by Canavier et al. [17] and Butera et al. [19], the maximal conductances of currents $\bar{g}_{\mathrm{i}}$ were multiplied by temperature-like scaling factor for currents $\rho(\mathrm{T})\left(\overline{\mathrm{g}}_{\mathrm{i}} \times \rho(\mathrm{T})=\overline{\mathrm{g}}_{\mathrm{i}} \times 1.3^{\frac{\mathrm{T}-\mathrm{T}_{0}}{10^{\circ} \mathrm{C}}}, \mathrm{i}=\mathrm{Na}, \mathrm{Ca}, \mathrm{K}, \mathrm{SI}, \mathrm{NS}\right)$, and the relaxation time constant $\mathrm{T}_{j}$ were multiplied by temperature-like scaling factor for ionic kinetics $\mathrm{T}_{\mathrm{j}}\left(\left(1 / \mathrm{T}_{\mathrm{j}}\right) \times \phi(T)=\left(1 / \mathrm{\tau}_{\mathrm{j}}\right) \times 3^{\frac{\mathrm{T}-\mathrm{T}_{0}}{10^{\circ} \mathrm{C}}}, \mathrm{j}=\mathrm{m}, \mathrm{h}, \mathrm{d}, \mathrm{f}, \mathrm{n}, \mathrm{l}, \mathrm{s}, \mathrm{b}\right)$. In order to obtain computer simulation of temperaturedependent bursting patterns, it was necessary to select three good data files obtained from experiment $\mathrm{A}$ at different temperatures; $18.1^{\circ} \mathrm{C}, 22.1^{\circ} \mathrm{C}$, and $27.9^{\circ} \mathrm{C}$. The figures drawn by using these data files were expressed by symbols L1, M1 and $\mathrm{H} 1$, respectively, shown on the panels at Figure 8A and B. After temperature values shown on these panels should be substituted for $\mathrm{T}$ in the temperature-dependent scaling factors, $\rho(\mathrm{T})$ and $\phi$ ( $\mathrm{T}$ ) involved in these modified models $\left(\mathrm{T} 0=23^{\circ} \mathrm{C}\right)$, we could get these figures drawn in red solid lines and these were shown on these panels. In the results of simulations with these modified models, it could be found that burst duration and number of spike during burst increased as temperature increased. But these results were not consistent with our experimental results. So, although the model presented by Canavier et al. [17] and Butera et al. [19] were based on experimental data to a great extent, it might be thought that these models are not appropriate for investigation about the ionic mechanism underlying the temperature-dependent change in bursting pattern from experiments with bursting pacemaker neurons in the abdominal ganglia of Aplysia juliana.

In a similar way, we could get three figures shown on Figure $8 \mathrm{C}$ by simulation using the modified models that were developed by Bertram [18]. Although the fact that the values of burst duration and number of spike during burst that were obtained from simulation by using this modified model decreased as temperature increased was consistent with our experimental results in a small temperature range, it was very difficult to simulate the temperature-dependent changes of bursting patterns in a large temperature range; from $18.1^{\circ} \mathrm{C}$ to $27.9^{\circ} \mathrm{C}$. So we tried to simulate temperature-dependent bursting patterns in a small temperature range from $22.2^{\circ} \mathrm{C}$ to $25.8^{\circ} \mathrm{C}$ and the results were shown on Figure 8D. But these results were also not consistent with our experimental results. Namely, the values of interspike interval 


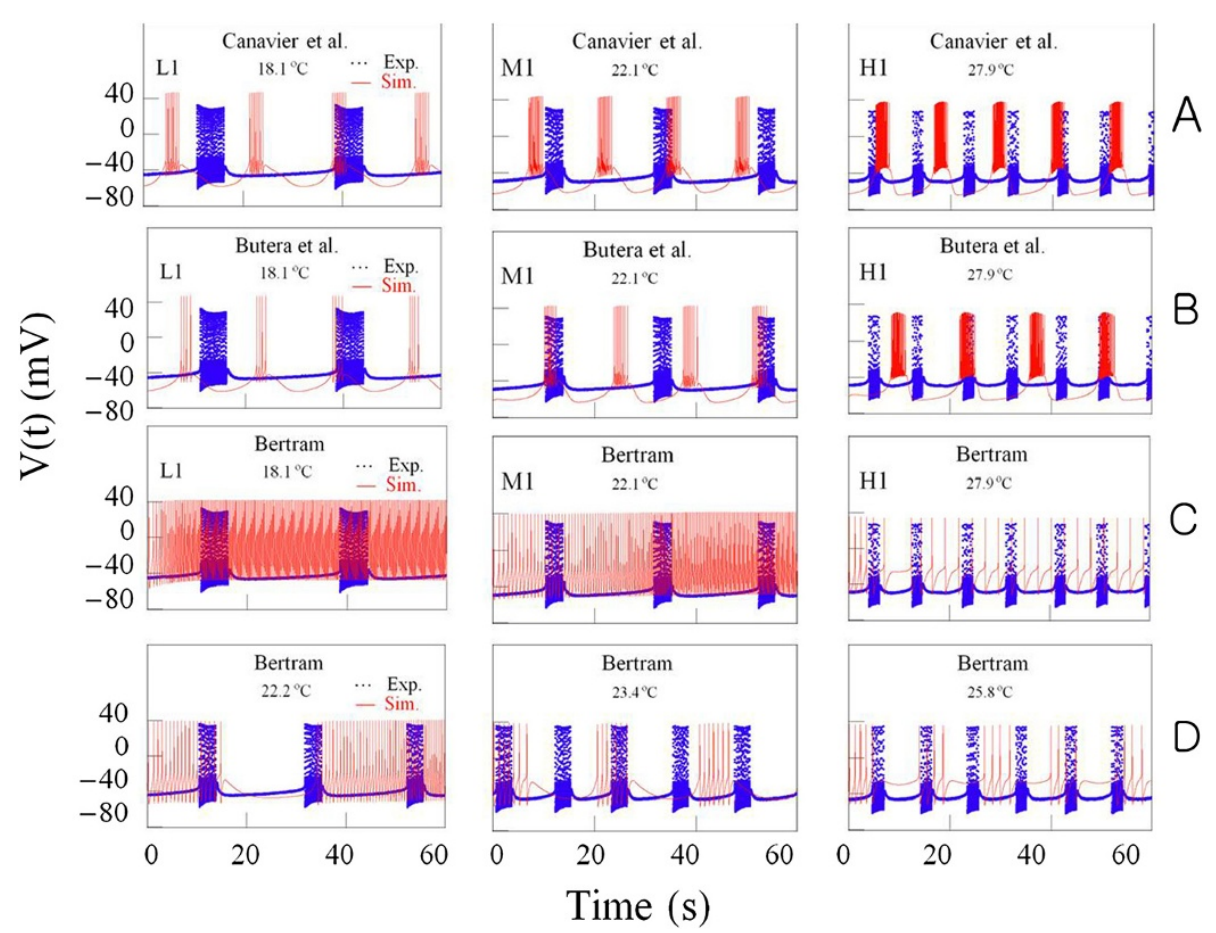

Figure 8 Time series of bursting activity drawn by using the data for the experiments $\mathrm{A}$ and computer simulations at different temperatures. Experimentally recorded spike trains (blue, dotted line) and the result from computer simulations of modeling (red, solid line) are compared. The results from simulation using the equations developed by Canavier et al. [17] and modified by us with temperature-dependent scaling factors at the temperatures, $18.1^{\circ} \mathrm{C}, 22.1^{\circ} \mathrm{C}$ and 27.8 are shown on panels $\mathrm{L} 1, \mathrm{M} 1$, and $\mathrm{H} 1$ respectively, in the upper traces (A). Those using the models revised by Butera et al. [19] and Bertram [18] and modified by us with the same temperature dependent scaling factors are shown in the intermediate traces $(\mathbf{B}, \mathbf{C})$. The comparison of those using the equations revised by Bertram and modified by us are shown in the lowest panels (D) at the temperatures $22.2^{\circ} \mathrm{C}, 23.4^{\circ} \mathrm{C}$ and $25.8^{\circ} \mathrm{C}$ with small range of temperature changes.

during burst obtained from simulations were larger than those got from experiments, and these values could not be reduced: the values of the other bursting parameters might be given rise to inconsistencies with our experimental results. Thus, it might be thought that this model was not also appropriate for investigation about that.

Any way, it was shown that that $\mathrm{I}_{\mathrm{K}(\mathrm{Ca})}$ is not involved in burst termination in Aplysia bursting neurons Kramer and Zucker [30]. Even though calcium-activated potassium channels are located in the soma of R15 neuron, it was not necessarily proved that this channel was important for bursting pattern. Next, we have to discuss on the following question: are there any other experimental evidences suggesting that $\mathrm{I}_{\mathrm{K}(\mathrm{Ca})}$ is involved in bursting pattern of Aplysia neurons, particularly R15 neuron? Although we didn't yet find any one of research papers that were published after year 1985, it might be necessary to discuss whether the figures that we have suggested in this paper could be given us any chance to run back over the experimental evidence on it.

Now, it might be necessary to compare the temperaturedependent changes in burst firing patterns of subthreshold currents (or burst currents) involved in Plant model with those included in the other models. Time series of temperature-dependent subthreshold current activities $\left(\rho(T) \cdot I_{S I}\right)$ simulated by using the equation of slow inward calcium current based on the model developed by Canavier et al. [17] at temperature values $18^{\circ} \mathrm{C}, 23^{\circ} \mathrm{C}$, and $28^{\circ} \mathrm{C}$ are shown together in blue lines (L), black lines $(\mathrm{M})$, and red lines $(\mathrm{H})$, respectively on panel $\mathrm{A}$ in Figure 9. Those $\left(\rho(T) \cdot I_{S I}\right)$ and $\left(\rho(T) \cdot\left(I_{C a}+I_{K(C a)}\right)\right)$ obtained from simulation data by using the model made by Butera et al. [19] and Plant [15] at the same temperature values are shown together on panel $\mathrm{B}$ and $D$ in Figure 9 , respectively. Those $\left(I_{D}+\rho(T) \cdot I_{N S R}\right)$ taken from simulation data calculated by using the model made by Bertram [18] at temperature values $22.3^{\circ} \mathrm{C}, 23^{\circ}$ $\mathrm{C}$, and $23.7^{\circ} \mathrm{C}$ are shown together on panel C in Figure 9. Next, it might be wanted to calculate the maximum values of temperature-dependent burst currents underlying the hyperpolarization of the inter-burst intervals, and then compare the values that were calculated by using Plant developed model with those by using the other models. The maximum values of these calculated by using Plant model at temperature values $18^{\circ} \mathrm{C}, 23^{\circ} \mathrm{C}$, and $28^{\circ} \mathrm{C}$ were $0.28 \mu \mathrm{A}, 0.12 \mu \mathrm{A}$, and $0.081 \mu \mathrm{A}$, respectively. The maximum values calculated by using Canavier et al. (Butera et al.) developed model at the same 

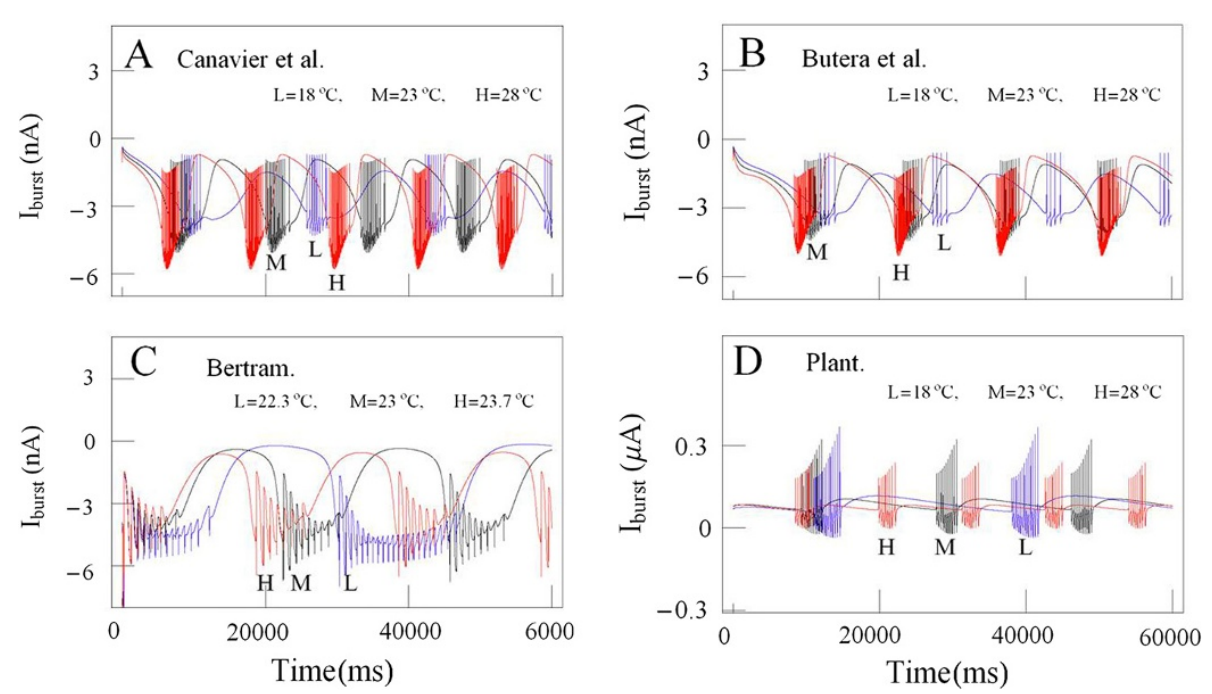

Figure 9 Comparison of temperature-dependent subthreshold current activities. (A) Time series of temperature-dependent subthreshold current activities $\left(\left.\rho(\mathrm{T}) \cdot\right|_{\mathrm{S} I}\right)$ simulated by using the results based on the model developed by Canavier et al. [17] at temperature values $18^{\circ} \mathrm{C}(\mathrm{L}$, blue lines)), $23^{\circ} \mathrm{C}\left(\mathrm{M}\right.$, black lines), and $28^{\circ} \mathrm{C}\left(\mathrm{H}\right.$, red lines) are shown together. (B) Those $\left(\rho(\mathrm{T}) \cdot\right.$ I $\left._{\mathrm{SI}}\right)$ obtained from simulation data at the same temperature values using the model made by Butera et al. [19] are shown together. (C) Those $\left(I_{D}+\rho(T) \cdot I_{N S R}\right)$ taken from simulation data at temperature values $22.3^{\circ} \mathrm{C}, 23^{\circ} \mathrm{C}$, and $23.7^{\circ} \mathrm{C}$ using the model made by Bertram et al. [18] are shown together. (D) Those $\left(\rho(T) \cdot\left(I_{C a}+I_{k(C a)}\right)\right)$ obtained from simulation data at temperature values $18^{\circ} \mathrm{C}, 23^{\circ} \mathrm{C}$ and $28^{\circ} \mathrm{C}$ using the model made by Plant [15] are shown together.

temperature values were $-1.62 \mathrm{nA},-0.9 \mathrm{nA}$, and $-0.75 \mathrm{nA}$ $(-1.5 \mathrm{nA},-1.1 \mathrm{nA}$, and $-0.77 \mathrm{nA})$, respectively. The maximum values calculated by using the model that Bertram developed at the temperature values $22.3^{\circ} \mathrm{C}, 23^{\circ} \mathrm{C}$, and $23.7^{\circ} \mathrm{C}$ were $-0.18 \mathrm{nA},-0.38 \mathrm{nA}$, and $-0.58 \mathrm{nA}$, respectively. These absolute maximum values calculated by using the models that Plant, Canavier, and Butera developed decreased as temperature increased, but those calculated by Bertram developed model increased as temperature increased. But more detailed analysis of these data remained as a challenge for future study.

Anyway, these facts might show that it was hard to clarify mathematically the temperature-dependent changes of bursting patterns at burst-firing neurons of Aplysia juliana with these three models involving many currents and a large number of static variables. So, it was necessary to investigate much simpler model with small number of currents and static variables such as Plant model.

At this stage, it might be useful to remind that temperature-dependent impulse patterns of mammalian cold receptors could be well simulated by using nonlinear differential equations involving $\mathrm{I}_{\mathrm{K}(\mathrm{Ca})}$. Different types of impulse patterns of mammalian cold receptors can be observed as a function of skin temperature: irregular and less frequent burst discharges, regular and frequent bursting patterns, and irregular single spike patterns are observed from low to high temperatures. These patterns could be simulated by Braun et al., and the Huber-Braun cold receptor model has been described in detail with 5 currents and 5 static variables (membrane potential and four voltage-dependent state-variables) [26,27,31-36]. This model consisted of two minimal sets of ionic conductances operating at different voltage levels with different delays and the leakage current. The first two voltage-dependent currents that generate the action potentials mean depolarizing current $\mathrm{I}_{\mathrm{Na}}$ and repolarizing current $\mathrm{I}_{\mathrm{K}}$. The next two voltage-dependent slow currents that generate subthreshold potential oscillations were slow depolarizing noninactivating $\mathrm{Na}^{+}$-current $\mathrm{I}_{\mathrm{Nap}}$ and slow repolarizing $\mathrm{Ca}^{2+}$-dependent $\mathrm{K}^{+}$-current $\mathrm{I}_{\mathrm{K}(\mathrm{Ca})}$ with voltage dependent activation of $\mathrm{Ca}^{2+}$-current. The temperature dependences were given by temperature-like scaling factors for the maximum conductances and the time constants, with reference temperature $T_{0}=25^{\circ} \mathrm{C}$. $\mathrm{Q}_{10}$ of 3.0 for the activation variable and $\mathrm{Q}_{10}$ of 1.3 for temperature dependences of maximum conductances were chosen.

Now, it would be necessary to look into another simple model to investigate the mechanisms of temperaturedependent changes of bursting patterns which share a few similarities with mammalian cold receptors. Plant model consisted of 5 currents and 6 static variables: 5 currents (fast sodium current $\mathrm{I}_{\mathrm{Na}}$, fast potassium current $\mathrm{I}_{\mathrm{K}}$, inward calcium current $\mathrm{I}_{\mathrm{Ca}}$, calcium-activated potassium current $\mathrm{I}_{\mathrm{K}(\mathrm{Ca})}$, and leakage current, $\mathrm{I}_{\mathrm{L}}$ ) and 6 static variables (membrane potential, intracellular concentration of $\mathrm{Ca}^{2+}$, and four voltage-dependent state-variables). There are two fast and slow processes in this model. The fast process had three components: the activation and inactivation variables for $\mathrm{Na}^{+}$channels " $\mathrm{m}$ " and " $\mathrm{h}$ ", respectively, and the 
activation of $\mathrm{K}^{+}$channels $\mathrm{n}$. The slow process had two components: a slow conductance for $\mathrm{Ca}^{2+}$-current " $\mathrm{X}$ ", and intracellular free calcium concentration "Ca". Not only Plant model had a simple structure, but also theoretical analyses of Plant's model were performed already $[16,37,38]$.

However, it is not easy to justify the reason of our choice of Plant model, because some papers excluded $\mathrm{I}_{\mathrm{K}}$ (Ca) as a key bursting current in R15 and focused on the inward current with slow activating and inactivating components. Plant model was based on the works of Gorman and Thomas [39], who demonstrated that $I_{K}$ (Ca) was linearly dependent on increasing concentration of intracellular calcium ions $\left(\mathrm{Ca}^{2+}\right)$ injected into the cytoplasm and expected to be activated during a burst. Chay [40] constructed mathematical model applicable to the Aplysia bursting neurons with involving the properties of $\mathrm{Ca}^{2+}$-activated $\mathrm{K}^{+}$channel: intracellular $\mathrm{Ca}^{2+}$ concentration increases gradually during activity to levels where it activates the $\mathrm{I}_{\mathrm{K}(\mathrm{Ca})}[10]$. Although Kramer and Zucker [30] concluded that $\mathrm{I}_{\mathrm{K}(\mathrm{Ca})}$ did not play a role in burst termination in bursting neurons of Aplysia, Adams and Levitan [41] did not exclude a role for $\mathrm{I}_{\mathrm{K}(\mathrm{Ca})}$ in the repolarization of action potential. But they asked the question: why a long-lasting $\mathrm{I}_{\mathrm{K}(\mathrm{Ca})}$ did not be activated by action potential? The plausible answer was the amount of calcium ions that entered into the cell during the activity of action potential was insufficient to generate it. Even if Canavier et al. [17] developed the model without $\mathrm{I}_{\mathrm{K}(\mathrm{Ca})}$, it was suggested as a limitations of this model that more experimental data of $\mathrm{I}_{\mathrm{K}(\mathrm{Ca})}$ were required for further investigation. Bertram [18] revised the model with $\mathrm{I}_{\mathrm{K}(\mathrm{Ca})}$ conductance depended only on the constant calcium concentration of the soma. Besides this, it has been known that the calcium activated potassium channels are located in $R_{15}$ soma [42] and electrode was inserted into the soma of the cell in the abdominal ganglion of A. juliana to measure the membrane potentials in our experiments. Thus, we cannot

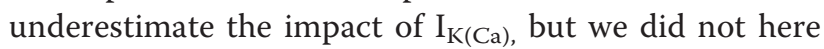
want to claim the quantitative application of Plant model, rather, we used it fr understanding the mechanism underlying the temperature dependence of busting patterns by computer simulations: it might be challenging to work later with a Rinzel and Lee's model based on the hypothesis that it is necessary for burst generation to consider an inward current which slowly inactivates as $\mathrm{Ca}^{2+}$ accumulates during the burst to the exclusion of $\mathrm{I}_{\mathrm{K}(\mathrm{Ca})}$ [16]. By making a comparison between experimental data and simulation results calculated with modified Plant equations, it was suggested that the mechanism underlying temperature-dependent bursting patterns of bursting pacemaker neurons at abdominal ganglion of Aplysia juliana might be derived from temperature-like scaling factors $\rho(\mathrm{T})$ and $\phi(\mathrm{T})$ for the maximum conductances and the time constants, respectively; together with reference temperature $\mathrm{T}_{0}=23^{\circ} \mathrm{C}$, $\mathrm{Q}_{10}$ of 3.0 for the activation variable, and $\mathrm{Q}_{10}$ of 1.3 for temperature dependences of maximum conductances.

Taken together, it was suggested that a modified Plant model could be used to simulate the temperaturedependent bursting activity of bursting pacemaker neurons in the abdominal ganglia of Aplysia juliana and to unravel the mechanism of temperature dependence in bursting patterns.

\section{Nomenclature}

$\mathrm{A}_{\mathrm{AB}}$ action potential amplitude

$\mathrm{A}_{\mathrm{AP}}$, ave, averaged action potential amplitude

$\mathrm{A}_{\mathrm{AP}, \max }$, maximum action potential amplitude

$\mathrm{Ca}$, slow change in intracellular free calcium concentration

Frequency, spontaneous firing frequency $(=1 / \mathrm{ISI})$

ISI, interspike interval $\left(=\Delta \mathrm{t}_{\mathrm{r} 1}+\Delta \mathrm{t}_{\mathrm{AP}, 1 / 2}+\Delta \mathrm{t}_{\mathrm{f} 2}\right)$

$\mathrm{I}_{\mathrm{Ca}}$, slow inward calcium current

$\mathrm{I}_{\mathrm{K}}$, fast potassium current

$\mathrm{I}_{\mathrm{K}(\mathrm{Ca})}$, calcium-activated potassium current

$\mathrm{I}_{\mathrm{L}}$, leak current

$\mathrm{I}_{\mathrm{Na}}$, fast sodium current

$\mathrm{T}_{0}$, reference temperature $\left(=23^{\circ} \mathrm{C}\right)$

$\mathrm{V}$, membrane potential

$\mathrm{V}_{\mathrm{Ca}}$, reversal potential for calcium current

$\mathrm{V}_{\mathrm{K}}$, reversal potential for potassium current

$\mathrm{V}_{\mathrm{L}}$, reversal potential for leak current

$\mathrm{V}_{\mathrm{Na}}$, reversal potential for sodium current

$\mathrm{V}_{\mathrm{np}}$, membrane potential at the negative peak

$\mathrm{V}_{\mathrm{pp}}$, membrane potential at the positive peak

$\Delta t_{r 1}$, first half of the rising phase of AP

$\Delta t_{r 2}$, last half of the rising phase of AP

$\Delta t_{\mathrm{f} 1}$, first half of the falling phase of AP

$\Delta t_{\mathrm{f} 2}$, last half of the falling phase of AP

$\Delta t_{\mathrm{AP}, 1 / 2}, \mathrm{AP}$ half-width duration $\left(=\Delta \mathrm{t}_{\mathrm{r} 2}+\Delta \mathrm{t}_{\mathrm{f} 1}\right)$

$\theta_{1}$, inverse tangent of the ratio of half $\mathrm{A}_{\mathrm{AP}}$ to $\Delta \mathrm{t}_{\mathrm{r} 2}$

$\theta_{2}$, inverse tangent of the ratio of half $\mathrm{A}_{\mathrm{AP}}$ to $\Delta \mathrm{t}_{\mathrm{f} 1}$

$\overline{\mathrm{g}}_{\mathrm{Ca}}$, maximal conductance for calcium ion current

$\overline{\mathrm{g}}_{\mathrm{K}}$, maximal conductance for potassium ion current

$\overline{\mathrm{g}}_{\mathrm{L}}$, maximal conductance for leak current

$\overline{\mathrm{g}}_{\mathrm{Na}}$, maximal conductance for sodium ion current

$h$, voltage-dependent inactivation variable for sodium channel; $h_{\infty}=$ steady state value of inactivation $h$

$m$, voltage-dependent activation variable for sodium channel; $\mathrm{m}_{\infty}=$ steady state value of activation $\mathrm{m}$

$n$, activation variable for potassium channel; $\mathrm{n}_{\infty}=$ steady state value of activation $n$

$\mu_{\mathrm{m}}$, constant value involved in the defining equation for $\mathrm{m}_{\infty}$ $\mu_{h}$, constant value involved in the defining equation for $h_{\infty}$ $\mu_{\mathrm{n}}, \nu_{\mathrm{n}}$, constant values involved in the defining equation for $\mathrm{n}_{\infty}$ 
$\alpha, \beta, \gamma, \delta$, constant values involved in the defining equation for steady state values of activation (inactivation) variables and relaxation constants

$1 / \lambda$, maximal relaxation time constant of $h$ and $n$

$\overline{\mathrm{\tau}}_{\mathrm{n}}$, maximal relaxation time constant of $\mathrm{n}$

$\tau_{h}$, relaxation constant of $h$

$\tau_{X}$, relaxation constant of $X$

$\tau_{n}$, relaxation constant of $n$

$X$, slowly activating conductance for calcium current; $X_{\infty}=$ steady state value of activation $X$

$\rho^{-1}$, estimation for the time-constant of the Ca-equation $\rho(\mathrm{T})$, temperature-dependent scaling factor; $\rho(\mathrm{T}) \equiv 1.3 \frac{\mathrm{T} \cdot \mathrm{T}_{0}}{10^{\circ} \mathrm{C}}$ $\phi(\mathrm{T})$, temperature-dependent scaling factor; $\phi(\mathrm{T}) \equiv 3 \frac{\mathrm{T}-\mathrm{T}_{0}}{10^{\circ} \mathrm{C}}$ $\mathrm{I}_{\mathrm{SI}}$, slow inward $\mathrm{Ca}^{2+}$-current

$\mathrm{I}_{\mathrm{NS}}$, nonspecific cation current

$I_{R}$, anomalous rectifier current

$\mathrm{I}_{\mathrm{NaCa}}, \mathrm{Na}^{+}-\mathrm{Ca}^{2+}$ exchanger current

$\mathrm{I}_{\mathrm{NaK},} \mathrm{Na}^{+}-\mathrm{K}^{+}$pump current

$\mathrm{I}_{\mathrm{CaP}}, \mathrm{Ca}^{2+}$ pump current

$\mathrm{I}_{\mathrm{K} 1}$, inhibitory potassium current

$\mathrm{I}_{\mathrm{NSR}}$, calcium current which initiate the burst

$\mathrm{I}_{\mathrm{D}}$, cation-nonspecific current

$I_{R}$, potassium current which is activated only near the potassium equilibrium potential

$\mathrm{I}_{\text {Nap }}$, slow depolarizing noninactivating $\mathrm{Na}^{+}$-current

\section{Competing interests}

The authors declare that they have no competing interests.

\section{Authors' contributions}

N.G.H. carried out electrophysiological experiments, performed computer simulation of experimental data, and drafted the manuscript. K.H.H. and K.B. $\mathrm{H}$. participated in computer programming for simulation of experimental data. K.L. drafted and revised the manuscript. All authors read and approved the final manuscript.

\section{Acknowledgements}

This work was supported by a research grant from the Sochun Academic Research Fund of Jeju National University in 2012. K.L. was supported by Basic Science Research Program NRF-2013R1A1A3010216 and NRF-2013R1A3A1072702 funded by the Ministry of Education, Science and Technology

\section{Author details \\ 'Department of Physics and Research Institute for Basic Sciences, Jeju National University, Jeju 690-756, South Korea. ${ }^{2}$ School of Medicine, The Catholic University of Korea, Seoul 137-701, South Korea. ${ }^{3}$ Department of Biological Sciences, Korea Advanced Institute of Science and Technology, Daejeon 305-701, South Korea. ${ }^{4}$ Department of Anatomy, Brain Science \& Engineering Institute, Kyungpook National University Graduate School of Medicine, 2-101, Dongin-dong, Jung-gu, Daegu 700-842, South Korea.}

Received: 28 May 2014 Accepted: 28 June 2014

Published: 22 July 2014

\section{References}

1. Hyun NG, Hyun KH, Lee K, Kaang BK: Temperature dependence of action potential parameters in Aplysia neurons. Neurosignals 2012, 20:252-264.

2. Murray RW: The effect of temperature on the membrane properties of neurons in the visceral ganglion of Aplysia. Comp Biochem Physiol 1966, 18:291-303.
3. Stephens PJ, Frascella PA, Mindrebo N: Effects of ethanol and temperature on a crab axon action potentials: a possible mechanism for peripheral spike generation. J Exp Biol 1983, 103:289-301.

4. Heitler WJ, Edwards DH: Effect of temperature on a voltage-sensitive electrical synapse in crayfish. J Exp Biol 1998, 201:503-513.

5. Frankenhaeuser B, Moore LE: The effect of temperature on the sodium and potassium permeability changes in myelinated nerve fibres of Xenopus laevis. J Physiol 1963, 169:431-437.

6. Dalton JC, Hendrix DE: Effects of temperature on membrane potentials of lobster giant axon. Am J Physiol 1962, 202:491-494.

7. Burrows M: Effects of temperature on a central synapse between identified motor neurons in locust. J Comp Physiol A 1989, 165:687-695.

8. Kerkut GA, Ridge RM: The effect of temperature changes on the activity of the neurons of the snail Helix aspersa. Comp Biochem Physiol 1962, 5:283-295.

9. Hodgkin AL, Katz B: The effect of temperature on the electrical activity of the giant axon of the squid. J Physiol 1949, 109:240-249.

10. Gorman ALF, Hermann A, Thomas MV: Ionic requirements for membrane oscillations and their dependence on the calcium concentration in a molluscan pace-maker neurone. J Physiol 1982, 327:185-217.

11. Adams WB: Slow depolarizing and hyperpolarizing currents which mediate bursting in Aplysia neuron R15. J Physiol 1985, 360:51-68.

12. Adams WB, Benson JA: The generation and modulation of endogenous rhythmicity in the Aplysia bursting pacemaker neuron R15. Prog Biophys molec Biol 1985, 46:1-49.

13. Plant RE, Kim M: On the mechanism underlying bursting in the Aplysia abdominal ganglion R15 cell. Math Biosci 1975, 26:357-375.

14. Plant RE, Kim M: Mathematical description of a bursting pacemaker neuron by a modification of the Hodgkin-Huxley equations. Biophys $J$ 1976, 16:227-224.

15. Plant RE: Bifurcation and resonance in a model for bursting nerve cells. J Math Biology 1981, 11:15-32.

16. Rinzel J, Lee YS: Dissection of a model for neuronal parabolic bursting J Math Biol 1987, 25:653-675.

17. Canavier CC, Clark JW, Byrne JH: Simulation of the bursting activity of Neuron R15 in Aplysia: role of ionic currents, calcium balance, and modulatory transmitters. J Neurophysiol 1991, 66:2107-2124.

18. Bertram R: A computational study of the effects of serotonin on a molluscan neuron. Biol Cybern 1993, 69:257-269.

19. Butera RJ, Clark JW, Canavier CC, Baxter DA, Byrne JH: Analysis of the effects of modulatory agents on a modeled bursting neuron: dynamic interactions between voltage and calcium dependent systems. J Comput Neurosci 1995, 2:19-44.

20. Carpenter DO: Temperature effects on pacemaker generation, membrane potential, and critical firing threshold in Aplysia neurons. J Gen Physiol 1967, 50:1469-1484.

21. Fletcher SD, Ram JL: High temperature induces reversible silence in Aplysia R15 bursting pacemaker neuron. Comp Biochem Physiol A 1991, 98:399-405.

22. Wu J, Fisher RS: Hyperthermic spreading depressions in the immature rat hippocampal slice. J Neurophysiol 2000, 84:1355-1360.

23. Kim JA, Connors BW: High temperatures alter physiological proper-ties of pyramidal cells and inhibitory interneurons in hippocampus. Front Cell Neurosci 2012, 6:27.

24. Orlowski JP, Erenberg G, Lueders H, Cruse RP: Hypothermia and barbiturate coma for refractory status epilepticus. Crit Care Med 1984, 12:367-372.

25. Hyun NG, Hyun KH, Hyun KB, Han JH, Lee K, Kaang BK: A computational model of the temperature-dependent changes in firing patterns in Aplysia neurons. Korean J Physiol Pharmacol 2011, 15:371-382.

26. Braun HA, Huber MT, Dewald M, Schäfer K, Voigt K: Computer simulation of neural signal transduction: the role of nonlinear dynamics and noise. Int J Bifur Chaos 1998, 8:881-889.

27. Finke C, Freund JA, Rosa E, Braun HA, Feudel U: On the role of subthreshold currents in the Huber-Braun cold receptor model. Chaos 2010, 20:045107-045107-10.

28. Chay TR, Cook DL: Endogenous bursting patterns in excitable cells. Math Biosci 1988, 90:139-1530.

29. Bertram R: Reduced-system analysis of the effects of serotonin on a molluscan burster neuron. Biol Cybern 1994, 70:359-368.

30. Kramer RH, Zucker RS: Calcium-induced inactivation of calcium current causes the inter-burst hyperpolarization of Aplysia bursting neurons. J Physiol 1985, 362:131-160. 
31. Braun W, Eckhardt B, Braun HA, Huber M: Phase-space structure of thermoreceptor. Phys Rev E 2000, 62:6352-6360.

32. Braun HA, Huber MT, Anthes N, Voigt K, Neiman A, Pei X, Moss F: Interaction between slow and fast conductances in the Huber/Braun model of cold-receptor discharges. Neurocomputing 2000, 32-33:51-59.

33. Braun HA, Huber MT, Anthes N, Voigt K, Neiman A, Pei X, Moss F: Noise-induced impulse pattern modifications at different dynamical period-one situations in a computer model of temperature encoding. BioSystems 2001, 62:99-112.

34. Braun $\mathrm{H}$, Vogit $\mathrm{K}$, Huber M: Oscillations, resonances and noise: basis of flexible neuronal pattern generation. BioSystems 2003, 71:39-50.

35. Feudel U, Neiman A, Pei X, Wojtenek W, Braun H, Huber M, Moss F: Homoclinic bifurcation in a Hodgkin-Huxley model of thermally sensitive neurons. Chaos 2000, 10:231-239.

36. Mosekilde E, Sosnovtseva OV, Postnov D, Braun H, Huber MT: Noiseactivated and noise-induced rhythms in neural systems. Nonlin Stud 2004, 11:449-467.

37. Honerkamp J, Mutschler G, Seitz R: Coupling of a slow and a fast oscillator can generate bursting. Bull Math Biol 1985, 47:1-21.

38. Soto-Trevino C, Kopell N, Watson D: Parabolic bursting revisited. J Math Biol 1996, 35:114-128.

39. Gorman ALF, Thomas MV: Potassium conductance and internal calcium accumulation in a molluscan neuron. $J$ Physiol 1980, 308:287-313.

40. Chay TR: Electrical bursting and intracellular $\mathrm{Ca}^{2+}$ oscillations in excitable cell models. Biol Cybern 1990, 63:15-23.

41. Adams WB, Levitan IB: Voltage and ion dependences of the slow currents which mediate bursting in Aplysia neuron R15. J Physiol 1985, 360:69-93.

42. Lewis DV: Calcium-activated inward spike after-current in bursting neuron R15 of Aplysia. J Physiol Lond 1988, 395:285-302.

doi:10.1186/s13041-014-0050-5

Cite this article as: Hyun et al:: Temperature-dependent bursting pattern analysis by modified Plant model. Molecular Brain 2014 7:50.

\section{Submit your next manuscript to BioMed Central and take full advantage of:}

- Convenient online submission

- Thorough peer review

- No space constraints or color figure charges

- Immediate publication on acceptance

- Inclusion in PubMed, CAS, Scopus and Google Scholar

- Research which is freely available for redistribution 